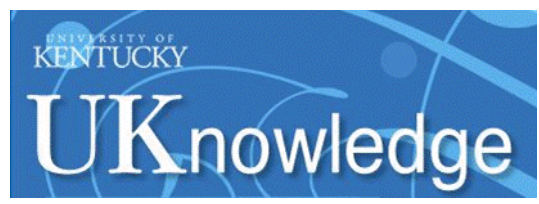

University of Kentucky

UKnowledge

\title{
CAFFEINE CONSUMPTION PATTERNS AND BELIEFS OF COLLEGE FRESHMEN
}

Gary Eugene Mcllvain

University of Kentucky, mcilvail2@marshall.edu

Right click to open a feedback form in a new tab to let us know how this document benefits you.

\section{Recommended Citation}

Mcllvain, Gary Eugene, "CAFFEINE CONSUMPTION PATTERNS AND BELIEFS OF COLLEGE FRESHMEN" (2008). University of Kentucky Doctoral Dissertations. 638.

https://uknowledge.uky.edu/gradschool_diss/638

This Dissertation is brought to you for free and open access by the Graduate School at UKnowledge. It has been accepted for inclusion in University of Kentucky Doctoral Dissertations by an authorized administrator of UKnowledge. For more information, please contact UKnowledge@lsv.uky.edu. 


\section{ABSTRACT OF DISSERTATION}

Gary Eugene McIlvain

The Graduate School

University of Kentucky

2008 
CAFFEINE CONSUMPTION PATTERNS AND BELIEFS OF COLLEGE FRESHMEN

\author{
ABSTRACT OF DISSERTATION \\ A dissertation submitted in partial fulfillment of the \\ requirements for the degree of Doctor of Education in the \\ College of Education \\ at the University of Kentucky \\ By \\ Gary E. McIlvain \\ Ashland, Kentucky \\ Director: Dr. Melody Noland, Professor of Kinesiology and Health Promotion \\ Lexington, Kentucky \\ 2008
}

Copyright (C) Gary Eugene McIlvain 2008 
ABSTRACT OF DISSERTATION

\section{CAFFEINE CONSUMPTION PATTERNS AND BELIEFS OF COLLEGE FRESHMEN}

Recently, energy drinks that contain high caffeine content without any age restrictions for purchase, have been introduced into the U.S. market. Caffeine consumption in the U.S. has increased dramatically, resulting in an increase in emergency room visits and calls to poison control centers. This increase in energy drink consumption, along with the traditional coffees, teas, and soft drinks that people consume regularly, have pushed caffeine consumption to new highs in a multi-billion dollar market.

The purpose of this study was to determine (1) the amount of caffeine consumed by a sample of freshmen students at Marshall University, (2) their beliefs regarding caffeine consumption, (3) reported perceived benefits and adverse effects of caffeine consumption, (4) reasons for consuming or refraining from consuming caffeine, and (5) predictors of high and low caffeine consumption

Eighty three percent reported having at least one sign/symptom of caffeine intoxication in the past while 51\% reported having at least one sign/symptom of caffeine withdrawal. More than $78 \%$ consumed above the recommended $200 \mathrm{mg}$ of caffeine per day. The mean milligram of caffeine consumed per day in the present study was 849.86, which computes to $12.08 \mathrm{mg} / \mathrm{kg} /$ day. This was three to five times the recommended amount. Father's social index, participation in organized activity in college, and three items for concentration, keep awake, and wake up (items of alertness) were statistically significant predictors of caffeine consumption. Respondents that participated in organized activity while in college consumed on average $60.7 \%$ more caffeine than those who indicated they did not participate in organized activity while in college. Every time the three items for concentration, keep awake, and wake up increased one point, caffeine consumption increased on average $41.1 \%$. Females were more likely to believe that caffeine is addictive than their male counterparts. Beliefs of negative consequences of caffeine consumption did not deter caffeine consumption. Slightly more than $60 \%$ reported using caffeine to wake up in the morning and more than $76 \%$ reported using it to stay awake. This was consistent with reported beliefs of the effects of caffeine consumption. Implications for education were discussed. 
KEYWORDS: Caffeine, Caffeine Consumption, Guarana, Caffeineism, Caffeine Intoxication

Gary Eugene McIlvain Student's Signature

$\underline{07-21-08}$

Date 


\section{CAFFEINE CONSUMPTION PATTERNS AND BELIEFS OF COLLEGE FRESHMEN}

By

Gary Eugene McIlvain

Dr. Melody Noland

Director of Dissertation

Dr. Richard Riggs

Director of Graduate Studies

$\underline{07-21-2008}$ 


\section{RULES FOR THE USE OF DISSERTATIONS}

Unpublished dissertations submitted for the Doctor's degree and deposited in the University of Kentucky Library are as a rule open for inspection, but are to be used only with due regard to the rights of the authors. Bibliographical references may be noted, but quotations or summaries of parts may be published only with the permission of the author, and with the usual scholarly acknowledgments.

Extensive copying or publication of the dissertation in whole or in part also requires the consent of the Dean of the Graduate School of the University of Kentucky.

A library that borrows this dissertation for use by its patrons is expected to secure the signature of each user.

Name

$\underline{\text { Date }}$ 


\section{DISSERTATION}

Gary Eugene McIlvain

The Graduate School

University of Kentucky

2008 
CAFFEINE CONSUMPTION PATTERNS AND BELIEFS OF COLLEGE FRESHMEN

\author{
DISSERTATION \\ A dissertation submitted in partial fulfillment of the \\ requirements for the degree of Doctor of Education in the \\ College of Education \\ at the University of Kentucky \\ By \\ Gary Eugene McIlvain, MS, ATC \\ Lexington, Kentucky \\ Director: Dr. Melody Noland, Professor of Kinesiology and Health Promotion \\ Lexington, Kentucky \\ 2008
}

Copyright (C) Gary Eugene McIlvain 2008 
This dissertation is dedicated to my loving wife Lisa and my parents, Charlie and Cindy McIlvain. 


\section{ACKNOWLEDGMENTS}

I would like to thank everyone who contributed to the completion of this dissertation. I am grateful and appreciate your insight and dedication that has enabled me to attain this achievement and milestone in my career and life. Dr. Noland, thank you for your continual guidance and commitment you demonstrated from academic planning and advising to guiding me through this writing process. Your endless time and encouragement is deeply appreciated. Dr. Dignan, Dr. Miller, and Dr. Riggs, thank you for your input, guidance, and for always being willing to listen and answer my many questions. Dr. Staten, thank you for accepting to fulfill the role of an outside examiner, your time and input is appreciated.

To the greatest statistician in the world, Dr. Bickel at Marshall University, thank you for your time and help with the statistical analysis. Thanks to Dr. Martin, Dr. Templeton, and Dr. Denman at Marshall University for making it possible to work at Marshall while completing this degree. Your support, input, and encouragement are appreciated.

Most of all, I give my love, admiration, and appreciation to my wife Lisa. Thank you for your love, support, and encouragement that you gave me throughout this process and for allowing me to miss several commitments and not holding it against me. I love you Lisa, forever and ever. To my parents, Charlie and Cindy McIlvain, I love you and thank you for first raising me in Christianity and raising me to be an optimist. I owe you my determination and drive that I have in life. To my brother and sister, Chuck and Cynthia, thanks for the encouragement and I guess you two are next, good luck! 
Table of Contents

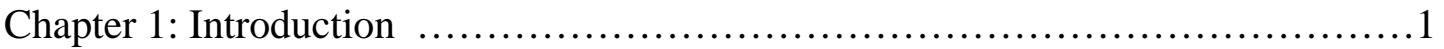

Justification for Studying Caffeine Consumption..........................

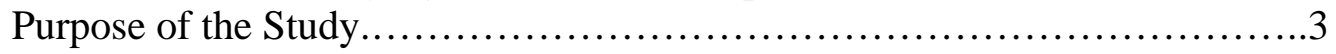

Research Questions/Hypotheses..........................................

Definition of Terms...................................................4

Chapter 2: Review of Literature............................................. 5

Introduction.......................................................... 5

Adolescents: Nutrition Knowledge and Behavior.......................... 5

Caffeine and College Students..........................................8

Sensation Seeking................................................... 9

Caffeine.............................................................. 10

Caffeine as an ergogenic aid........................................13

Caffeine Intoxication, Caffeinism, and DSM IV-TR Classification.............15

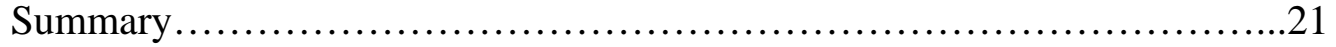

Chapter 3: Methodology....................................................22

Subjects.........................................................22

Instrument......................................................... 22

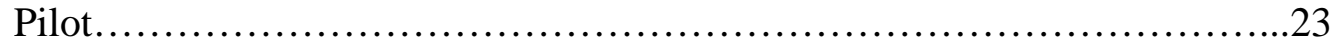

Sample Selection....................................................23

Procedures..........................................................24

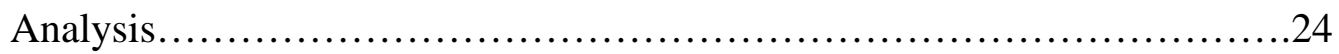

Chapter 4: Results, Discussion, and Limitations................................28

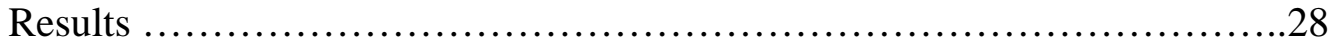

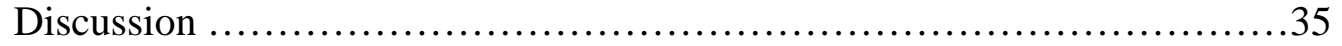

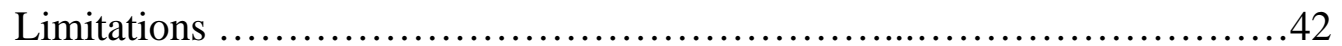

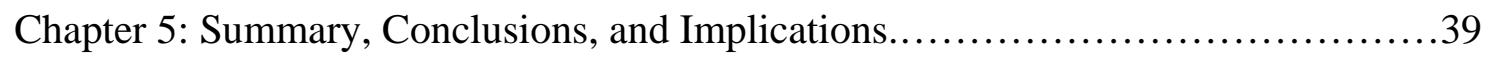

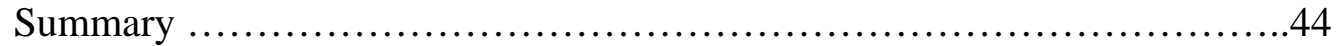

Conclusions .........................................................46

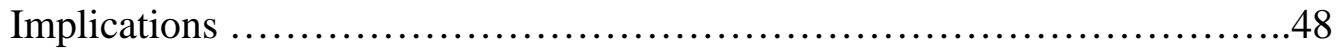

Appendices ................................................................... 44

Appendix A: Zuckerman's Sensation Seeking Scale.........................44

Appendix B: Brief Sensation Seeking Scale..............................47

Appendix C: Caffeine Content........................................48

Appendix D: American Academy of Pediatrics Policy Recommendation.......53

Appendix E: Survey Instrument..........................................54

Appendix F: Cover Letter..........................................66

Appendix G: Survey Scrip..............................................64

References............................................................... 53

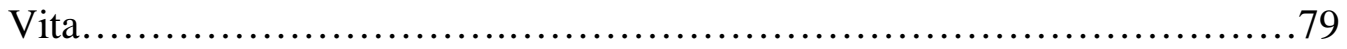




\section{LIST OF TABLES}

Table 1, Ethnicity of Participants...............................................28

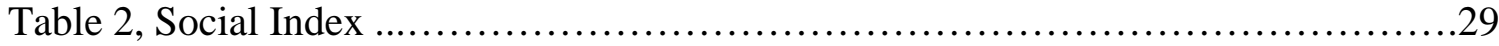

Table 3, Principal Component Analysis for Father's and Mothers Social Index .........29

Table 4, Brief Sensation Seeking Scale .............................................30

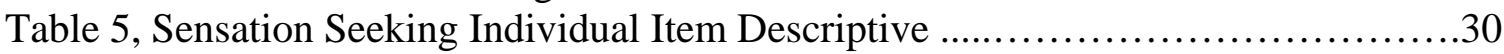

Table 6 Principal Component Analysis for "Risky" ................................. 31

Table 7, Caffeine Beliefs and use Frequencies ....................................

Table 8, Caffeine Intoxication and Withdrawal Frequencies, Percentages, and Means ...33

Table 9, Total Caffeine Means and Standard Deviations ..............................34

Table 10, Three Items for concentration, Keep Awake, and Wake Up....................35

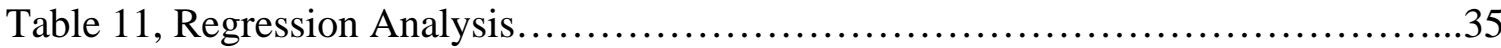

Table 12, T-tests for Sex Differences on Caffeine Beliefs............................36

Table 13, BSSS and Total Caffeine/Natural Log of Total Caffeine Correlation............36

Table 14, Hollingshead's Index of Social Position Classification Descriptions ...........41 


\section{LIST OF FILES}

McIlvain_Gary.pdf.............................................212 KB 


\section{Chapter 1}

Introduction

"Caffeine is the most commonly used mood-altering drug in the world" (Juliano, \& Griffiths, 2005, p403). Even though caffeine is widely accepted it has been scrutinized for centuries in the United States due to unhealthy effects to the human body. With the recent explosion in the energy drink market (Tibbles, 2006 ), increased soft drink consumption among youth (CSPI, 1998), and as Kaczmarski reported, the media targeting youth in advertising (Tibbles, 2006; Molnar, 1999) there is a growing concern about youth consuming large amounts of caffeine.

Research has shown that adolescents typically engage in many unhealthy behaviors such as substance abuse and risky sexual behavior. Adolescents also have many unhealthy nutritional behaviors which are fueled by increasing options given to American youth. Many schools have vending machines and/or school stores (French, Story, Fulkerson, \& Gerlach, 2003; Shannon, Story, Fulkerson, \& French, 2002). This usually offers the high school student a wide array of unhealthy choices, including snacks and soft drinks. The consumption of soft drinks (with many soft drinks having caffeine) is of growing concern due to the lack of nutritional sustenance (Fried \& Nestle, 2002). Adolescence is one of the most dynamic times of a person's life (Story, NeumarkSztainer, \& French, 2002) in physical development and acquiring lifetime habits, and one of the most opportune times to adopt a healthy behavior. All the while, soft drink companies target schools and younger children to create loyalty to their particular brand by offering schools cash payments for advertising rights, and by offering free scoreboards for athletic events, profits from sales, and other types of payments (Fried \& Nestle, 2002).

Drinks high in caffeine often use marketing schemes that target sensation seekers. This is evident when watching the X-games, which are games that offer extreme competitions such as motorcycle vaulting (similar to pole vaulting in track and field, but done on a motorcycle), motorcycle stunting, bicycle stunting, and skateboarding. The Xgames are often sponsored by Red Bull energy drink or other high caffeine drinks. It is 
also evident by watching commercials or being on web sites such as Red Bull, Mountain Dew, or Monster energy drink to see sales ads such as "Red Bull, it gives you wings," or "Do the Dew," and "Let your inner man out" respectively. Sensation seekers often get bored easily, prefer change, are risk takers, and enjoy intense sensations and experiences for the sake of the experience (Zuckerman, 1972). This population will generally try a product if it promises a new and exciting experience.

Justification for Studying Caffeine Consumption

There are a number of reasons why caffeine consumption needs more study: First, there are a lack of data regarding college freshmen and caffeine consumption. Second, there is increased evidence of adverse physical and behavioral effects related to caffeine such as sleep deprivation, increased heart rate, increased blood pressure, central nervous system disorders, vasodilation, trembling, seizures, urticaria (severe allergic reaction), headaches, increased body temperature, inverse relationship to grades, disruption of coordination of complex tasks, sleep apnea, nervousnessness, hyperactivity, agitation, anxiety, attention disorders, and disruptive behaviors (Bardwell et al , 2000; Catlin \& Hatton, 1991; Dews, 1984; Fernandez-Nieto \& Quirce, 2002; Hering-hanit \& Gadoth, 2003; Katholi, et al, 2003; Pollak \& Bright, 2003; Stebbins, Daniels, \& Lewis, 2001; Zagnoni \& Albano, 2002). Third, there is a call from the American Academy of Pediatrics (2005) for programs to reduce usage of sport enhancing aids that claim to "give an edge” (p.1103), "increase strength, power, speed or endurance” (p.1104), or those aids used for weight control. One of these ergogenic aids is caffeine. Fourth, the Canadian Centre for Drug-Free Sport (1993), Llorens (1998), and Tymowski and Somerville (2002) reported the use of caffeine to enhance athletic performance among Canadian youth. Fifth, there has been a sharp increase in soft drink consumption among U.S. youth and many of these soft drinks contain caffeine (Cavadini, Siega-Riz, \& Pipkin, 2000; Jacobson, 1998; Kassem, Lee, Modeste, \& Johnston, 2003). Sixth, Simmons, reported that $31 \%$ of U.S. teens are drinking energy drinks, most of which have caffeine as a main ingredient (Tibbles, 2006). This is an increase of 3 million teens in the past three years, resulting in an $80 \%$ increase in the energy drink market (Tibbles, 2006). Finally, the FDA has issued a call that there is a lack of data regarding the 
possible physical consequences of caffeinated beverages and a clearer understanding is needed about the reasons why young people use energy drinks and the contexts in which they are used (Amelia, 2006). In addition to the energy drink market explosion, it has been reported that the number of calls to Poison Control Centers due to caffeine overdose has increased (Crouch, B., Caravati, E., \& Booth, J. (2004); Tibbles, 2006). Crouch, et al (2004) reported that more than $23 \%$ of all substances reported by Poison Control Centers for ages 6-19 was caffeine.

For all of these reasons, there is a need for data on American youth's caffeine consumption. By gaining insight into caffeine consumption among incoming college freshmen, researchers and health promoters can gain a description of caffeine consumption rates and beliefs of the effects of caffeine among students who recently graduated from high school.

Purpose of the Study

The purpose of this study was to determine (1) the amount of caffeine consumed by a sample of freshmen students at Marshall University, (2) their beliefs regarding caffeine consumption, (3) reported perceived benefits and adverse effects of caffeine consumption, (4) reasons for consuming or refraining from consuming caffeine, and (5) predictors of high and low caffeine consumption. These data will give health promotion professionals information which will be useful in planning interventions.

\section{Research Questions}

The following research questions were raised for this study.

1. What is the average amount of caffeine consumed daily among a group of college students?

2. What beliefs do these college students have regarding caffeine (e.g. effects on health, performance enhancement, weight loss aid, and aid in staying awake or alert)?

3. What are the perceived health benefits and adverse health effects of caffeine consumption?

4. What reasons do students give for either consuming or not consuming caffeine? 
5. Are there predictors of high and low caffeine consumption (e.g. SES, sex, sensation seeking, and participation in sport, band, academic or other extracurricular activities)?

Hypotheses

1. More than $50 \%$ of students will report having experienced at least one adverse health effects due to caffeine consumption.

2. Sensation seeking will be a predictor of caffeine consumption.

3. A linear composite of the following will predict caffeine consumption: Sex, SES, beliefs, and sensation seeking.

\section{Definition of Terms}

For the purposes of this study, the following terms were identified and defined:

Caffeine Consumption - ingesting caffeine by means of liquid or pill ingestion.

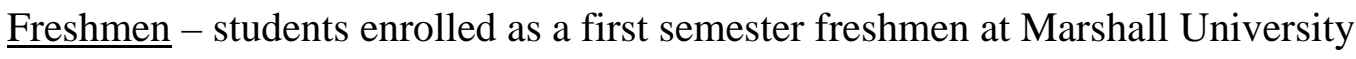
between the age of 18 and 20.

High Caffeine Consumption $->2.5 \mathrm{mg}$ of caffeine per kg of body weight per Day (Health Canada 2005).

Copyright (C) Gary Eugene McIlvain 2008 
Chapter 2

Review of the Literature

The purpose of this review is to discuss adolescent nutritional knowledge and behavior, the history of caffeine and its effect on human physiology and behavior, sensation seeking, caffeine as an ergogenic aid, caffeine intoxication, caffeinism, current adolescent caffeine use, and the DSM-IV Classifications with regard to caffeine intoxication, caffeinism, and other caffeine related disorders.

Adolescents: Nutrition Knowledge and Behavior

Substance abuse and proper nutrition continue to be of concern among adolescents. Unhealthy behaviors such as substance abuse, smoking, and risky sexual behavior are only a few of areas in which adolescents are exercising poor judgment, another is nutrition. Many schools have vending machines and/or school stores (French, Story, Fulkerson, \& Gerlach, 2003; Shannon, Story, Fulkerson, \& French, 2002). By this configuration the schools are offering students choices, but are often choices that are unhealthy. With an increase in overweight and obese adolescents, professionals are concerned with the increase of soft drink consumption. Especially since most soft drinks do not offer nutrition needed by growing adolescents and are high in calories (Fried \& Nestle, 2002). Adolescence is an opportune time to teach and engrain health behaviors. It is the time of ones life when physical and mental changes are rapid and lifetime behaviors are developed (Story, Neumark-Sztainer, \& French, 2002).

When addressing adolescents, and their nutritional knowledge and behavior, one must approach them with a different mindset than when dealing with adults. Most adolescents are still concrete thinkers and have yet to become abstract thinkers. They see the here and now, and often are oblivious to the future. Adolescents are more concerned with what is going on in the present time and often put more thought to appearance and perception than to their future. To reach adolescents one must not only show how something will benefit them, but also be able to demonstrate short-term benefits (Croll, Neumark-Sztainer, \& Story, 2001). Adolescence is viewed as a dynamic and complex transitional time in life. During this time every aspect of the adolescent's development and social growth is going through a transformation. Even with the importance put on 
nutrition, adolescents have poor nutritional habits (Story, Neumark-Sztainer, \& French, 2002).

Croll, Neumark-Sztainer, \& Story (2001) reported that when asked, adolescents relate nutrition to good foods/beverages and bad foods/beverages. They often relate eating out to bad nutrition and eating home cooked food (including fruits and vegetables) as good nutrition. Often the bad foods were listed as chips, candy, fast foods, pizza, soft drinks, sugary foods, and junk food. It was also reported that whether food is bad or not was often associated with whether or not the food comes in a wrapper. It was even viewed that high calorie foods, high cholesterol foods, steak, beef, ribs, and chicken with skin were unhealthy (Croll, Neumark-Sztainer, \& Story, 2001). Shannon, Story, Fulkerson, \& French (2002) report that 42\% of students had trouble identifying which foods were low-fat and that $48 \%$ of students would prefer that foods contain labels stating they are low-fat.

When describing what is healthy, adolescents often describe things that are cooked, eating at home with family members, and eating at a relative's house. Healthy eating is associated with eating vegetables without butter, watching fat intake, calorie intake, limiting caffeine, and not eating what is often referred to as a "bunch of junk" (Croll, Neumark-Sztainer, \& Story, 2001).

Dwyer, Evans, Stone, Feldman, \& et al (2001) report that $69 \%$ of students eat three meals a day while noting that the most often skipped meal was breakfast. Many who ate fewer meals per day tended to snack more often through out the day. The snacks included many with sweeteners which included soft drinks or sweets. With $79 \%$ of students eating lunch at school it is important to be aware of what school lunches and vending machines offer. Many schools offer a la carte programs and vending machines. Currently there are no federal nutritional guidelines for these programs as there are for school cafeterias (French, Story, Fulkerson, Gerlach, 2003).

Fried and Nestle (2002) reported that most adolescents have received information about healthy eating, the Food Guide Pyramid, and what is considered unhealthy. They have shown a general concept of what is healthy and unhealthy by relating foods and drinks to categorical bunching (e.g. food purchased out of vending machines or from fast 
food restaurants is unhealthy and home cooked food is healthy). Yet they still have unhealthy nutritional habits, with one fourth of students drink 26 ounces of soft drinks per day. And when in environments (schools) that provide vending/a la carte programs they are less likely to drink beverages such as juices, milk, or water (Fried \& Nestle, 2002). Ninety-three percent of students report that they choose what tastes best when choosing what to eat (Shannon, Story, Fulkerson, \& French, 2002).

Soft drinks offer a wide array of less-than-desirable ingredients. One of the ingredients scrutinized over the last several decades is caffeine. Katholi, Stormer, Stericker, Rankin, Katholi, \& Katholi (2003) brought caffeine to the forefront linking it to decreased performance in the classroom, sleep deprivation, and viewing the addictive properties and acceptance of caffeine as a gateway drug.

Americans, on average, consume 1.612 ounce cans of soft drinks per day for every man, woman, and child, doubling in consumption since 1974 (Jacobson, 1998). It has been reported by Kassem, Lee, Modeste, and Johnston (2003) that slightly more than $82 \%$ of adolescents are soft drink consumers and that children and adolescents consume 50\% more soft drinks than milk (Cavadini, Siega-Riz, \& Pipkin, 2000; Cullen, Ash, Warneke, \& Moor, 2002; French, Lin, \& Guthrie, 2003; Harnack, Stang, \& Story, 1999; Jacobson, 1998; Rampersaud, Bailey, \& Kauwell, 2003). Males tend to drink more soft drinks than do their female counterpart (Cavadini, Siega-Riz, \& Pipkin, 2000; French, Lin, \& Guthrie, 2003; Harnack, Stang, \& Story, 1999; Jacobson, 1998). Harnack, Stang, \& Story (1999) reported that race, sex, and urbanization were all significant when predicting soft drink consumption while Kassem, Lee, Modeste, \& Johnston (2003) reported that females chose soft drinks as the beverage of choice due to availability, taste, and that soft drinks will quench thirst.

With the increased consumption of soft drinks and decreased consumption of milk, a higher caloric intake is seen which has been associated with many health related issues. Decreased consumption of milk has been associated with the onset of osteoporosis (Cavadini, Siega-Riz, \& Pipkin, 2000; Jacobson, 1998). The increased amount of calories consumed in soda, due to the high levels of sugar, has been linked to 
Type-II diabetes (Shultze, Manson, Ludwig, et. al. 2004), obesity, and dental carries (Jacobson, 1998; Shultze, Manson, Ludwig, et. al. 2004).

Caffeine and College Students

College students ingest excessive and often times dangerous levels of caffeine (Johnson-Green, Douglass, et al, (1988). They reported that adverse biological and psychological side effects, such as muscle tremors, insomnia, stomach disorders, and fatigue, were being experience by high caffeine users. These users, specifically females, were knowledgeable of caffeine content which may indicate that females sought out drinks high in caffeine. Research completed by Pela (1989) found that the most commonly used drug among college students in Benin City, Nigeria was caffeine where 95 percent of student reported using caffeine in social settings. This research was supported by Egdochuku and Akerele (2007). They reported that Nigerian undergraduates most frequently abused caffeine among stimulants questioned. (This stimulant, caffeine, among others are associated with traits such as greed, fraud, examination malpractices, cultism, and character failure. Traits such as these are associated with violent demonstrations (Egdochuku \& Akerele, 2007).) Kristiansen, Levy-Milne, Barr, and Flint (2005) reported that Canadian University varsity athletes reported that the most common reasons given for caffeine use among males was to counteract tiredness, liking the taste, providing more energy, and to enhance performance. Females reported using caffeine for the taste, to counteract tiredness, to provide more energy, and to enhance performance (p. 203). Among the supplements, caffeine was "by far the most reported product causing side effects" (p 205). Celebrating achievement and facing a task requiring creativity were primary reasons for consuming caffeine in research completed by Venti and Chambliss (2000) comparing American and Australian student use of psychoactive substances.

Caffeine was reported to be statistically significant for females, but not men, in predicting a BMI (body mass index) gain when following students for one year (Adams \& Rini, 2007). However, Adams and Rini stated that it was unclear if it was caffeine or the calories associated with drinks with caffeine in them that led to the BMI gain. In a summary memorandum by Howes (2006) it is reported that one in 5 college students 
have used energy drinks in the previous year and these drinks are associated with higher levels of alcohol consumption, use of illicit drugs, and non-medical use of prescription drugs. Bradley and Petree (1990) reported that nearly 19 percent of college students had experienced five or more DSM-III caffeinism signs. A positive association between caffeinism symptoms and caffeine consumption was reported among those with expectations of caffeine-enhanced performance.

\section{Sensation Seeking}

Sensation seeking can be defined as "a trait defined by the seeking of varied, novel, complex, and intense sensations and experiences, and the willingness to take physical, social, legal, and financial risks for the sake of such an experience” (Zuckerman, 1994 p. 27). Reinforcement for the sensation seeker tends to be the sensory effects of external stimulation (Zuckerman, 1979). “The high-sensation seeker is sensitive to his or her internal sensations and chooses external stimuli that maximize them. Unusual sensations may be produced by emotions, drugs, and physical activities such as free-fall skydiving, scuba diving, or other activities involving speed and movement beyond the ordinary range (Zuckerman, 1979 p. 10). Parents are often frightened by children who are sensation seekers. Their children often alter and change games so they become dangerous, satisfying their sensation seeking while worrying parents (Zuckerman, 1979). The sensation seeker will become bored when stimuli and experiences become repetitive (Zuckerman, 1971; Zuckerman \& Bone, 1972). The following is Zuckerman's Sensation Seeking Scale - Form V (SSS-V) and scoring table as reported by Zuckerman (1979 p. 397-401). The SSS-V has four subscales with 10 sets of questions in each subscale. The subscales are Thrill and Adventure Seeking (TAS), Experience Seeking (ES), Disinhibition (Dis), and Boredom Susceptibility (BS) (Zuckerman, 1979 p. 102-103). Zuckerman \& Bone (1972 p. 309) report that the TAS items "express a desire to engage in outdoor sports or other activities involving elements of speed or danger," while the ES items "indicate a need for a broad variety of inner experience achieved through travel, drugs, music, art, and an unconventional style of life with an element of resistance to irrational authority and conformity," and the Dis is a “swinger factor, including items expressing a hedonistic, extraverted philosophy of 
"wild" parties, social drinking, variety in sexual life, and gambling," and the last subcategory of BS items indicate "a dislike of repetition, the routine and predictable, dull or boring people, and a restless reaction to monotony.”

Zuckerman’s (1979 p. 268-296) sensation seeking scale (see appendix A) has been positively correlated with varied sexual activities, drug and alcohol use, smoking and food preferences such as spicy, sour, and crunchy foods. With the length of Zuckerman's SSS-V questionnaire being difficult to administer with other questionnaires due to its length Hoyle, Stephenson, Palmgreen, Lorch, and Donohew (2002) and Stephenson, Hoyle, Palmgreen, \& Slater (2003) developed shorter scales to measure sensation seeking. These scales, called the Brief Sensation Seeking Scale (BSSS) and the Brief Sensation Seeking Scale-4 (BSSS-4) revealed statistically significant effects of both grade and Sex on all four measures of sensation seeking (TAS, ES, Dis, and BS) and appears to "adequately capture the tendencies of impulsive sensation seekers while also exhibiting a strong conceptual link to the original four-dimensional conceptualization of sensation seeking.” (Hoyle, Palmgreen, \& Slater, 2003 p. 284). The BSSS contains eight questions while the BSSS-4 contains only four questions and is ideal for use in large scale surveys. See Appendix B for the eight and four questions scales. Sensation seekers include those who like novel experiences, Gupegui, et al (20070 reported that novelty seeking was associated with heavy caffeine consumption (> 200mg/day) among adults. Miller (2008) reported that jock indentity (which included significant risk taking tendencies, especially in males, which is also associated with sensation seeking) was associated with energy drink consumption (most of which contain high levels of caffeine).

Caffeine

The history of caffeine dates back to about 4700 B.C. when tea was popular in China (Lecos, 1984). Caffeine was first isolated in Germany in 1820 by Runge. It was also reported to be isolated by Robiquete in 1823 and Pelletier in 1826 (Dews, 1984). Many other terms for caffeine were used until 1840 when "caffeine” became the predominant term. Earlier terms for caffeine included "cofeina" in 1823, "guaranin", "coffein" in 1826, and in 1827 the term "thein" was used by Oudry. In 1838 and finally 
in 1840 it was noted that all the substances thought to be different were actually the same as what we now know as caffeine (Dews, 1984). Caffeine, specifically caffeine metabolism, was being studied as early as 1850 . From that point on, caffeine has been scrutinized and studied by many different researchers with many different outcomes (Dews, 1984; Lecos, 1984). Historically caffeine was associated exclusively with coffee. In 1962 approximately 75\% of all people (ages ranging from 10 to those older than 60) were coffee drinkers. In 1987 this fell to 52\%, a decline of almost 25\%. At the same time the percentage of soft drink consumers was on the increase (Cavadini, Siega-Riz, \& Pipkin, 2000; Jacobson, 1998; Lecos, 1988).

See Appendix C for charts depicting the amount of caffeine in different beverages, foods, and drugs as reported by Erowid (2007) and by The Center For Science In The Public Interest (2007).

Caffeine has been at the center of controversy for decades. In the early 1980's the FDA issued warnings stating caffeine had been linked to birth defects, cancer, cardiovascular disease, behavioral problems, central nervous system disorders, reproductive problems, and nonmalignant breast lumps (Lecos, 1988).

Physiologically, caffeine has been shown to affect the cardiovascular system by raising blood pressure, raising pulse when in high volume, lowering pulse when in low volume, dilating vessels, increasing norepinepherine, epinephrine, \& rennin activity, causing trembling and seizures (Catlin \& Hatton, 1991; Zagnoni \& Albano, 2002), and urticaria (Fernandez-Nieto \& Quirce, 2002). Other effects of caffeine include indirect coronary artery dilation, headaches (Hering-Hanit \& Gadoth, 2003), sleep deprivation (Pollak \& Bright, 2003), and increases in body temperature (Stebbins, Daniels, \& Lewis, 2001). Heart rate often decreases during the first hour and then increased above baseline after the second hour after ingestion. Habitual users differ from non-habitual users due to tolerance. This was shown by blood pressure and heart rate returning to normal values with prolong use of caffeine (Dews, 1984; Garattini, 1993).

Caffeine has been shown to have effects on behavior as well. It has been shown to be inversely related to grades and decrease performance in the classroom (Katholi, Stormer, Stericker, Rankin, Katholi, \& Katholi, 2003), may disrupt coordination in 
complex tasks (Catlin \& Hatton, 1991), cause sleep disorders such as sleep apnea (Bardwell, Ziegler, Ancoli-Israel, Berry, Nelesen, Druning, \& Dimsdale, 2000), nervousness (Zagnoni \& Albano, 2002), hyperactivity, agitation, anxiety, withdrawal from play and interaction, attention disorders, and disruptive behaviors (Dews, 1984; Garattini, 1993).

The following are recommendations from Health Canada (2005) for maximum caffeine intake based on behavioral effects.

\begin{tabular}{|c|c|c|}
\hline * Children & $\begin{array}{l}\text { 4-6 years of age } \\
7-9 \text { years of age } \\
10-12 \text { years of age }\end{array}$ & $\begin{array}{l}45 \mathrm{mg} / \text { day } \\
62.5 \mathrm{mg} / \text { day } \\
85 \mathrm{mg} / \mathrm{day}\end{array}$ \\
\hline \multicolumn{2}{|c|}{ Women of child bearing age and/or pregnant } & 300mg/day \\
\hline
\end{tabular}

Kuchment (2007) reported that Roland Griffiths, neuroscientist at John's Hopkins University School of Medicine, reported that moderate doses (200-300mg/day) of caffeine for adults are not harmful but doses more than 500 - 600mg/day can cause side effects. These dosages are also supported by The Mayo Clinic (2007).

Caffeine ingested in lower doses has been shown to have positive effects. Brice and Smith (2002) found that doses of caffeine (either 65mg taken 4 times over a five hour period or a larger dose of 200mg taken at once) taken over time or all at once had a positive effect on alertness, improved performance on simple and choice reactive tasks, improved performance on a cognitive vigilance task and a task requiring sustained response and dual tracking/target detection. They also found that both doses increased anxiety. Biggs, Smith, Dorrian, Reid, Dawson, et al (2007) reported that small doses of caffeine (100 mg) increased driving performance, decreased driver perception of sleepiness and increased driver perception of driving performance. Koppelstaetter, Poeppel, Siedentopf, Ischebeck, Verius, Haala, et al (2007) reported that doses as little as 100mg of caffeine has a positive effect on frontopolar cortex of the brain. This part of the brain has been associated with attentional and executive functions such as cognitive conflict tasks, error detection/monitoring, working memory, planning, monitoring, and 
problem solving. It was reported that there was increased activity in the frontopolar cortex and postulated that this could benefit the tasks associated with that cortex. Barry, Johnstone, Clarke, Rushby, Brown, and Mckenzie reported that a single dose of 250mg of caffeine decreased simple auditory go/nogo tasks, but had no effect of omission or commission of errors thus it improved the processing related to response production and task performance. Maia \& Medonca (2002) suggest that those that consumed between 175-200mg of caffeine daily over time had a significantly reduced chance of developing Alzheimer's disease as those that consumed less than 100mg of caffeine per day. Another benefit of caffeine is using caffeine in a topical lotion. It has been been found to increase skin barrier function (Brandner, Behne, Huesing, \& Moll, 2006).

\section{Caffeine as an Ergogenic Aid}

Even with the documented negative effects of caffeine (Bardwell, Ziegler, AncoliIsrael, Berry, Nelesen, Druning, \& Dimsdale, 2000; Dews, 1984; Fernandez-Nieto \& Quirce, 2002; Garattini, 1993; Lecos, 1988; Katholi et al, 2003), it is often sought out by athletes as an ergogenic aid to enhance performance. Caffeine acts as a stimulant by releasing catecholamines such as epinephrine. Quantities, such as 3-5 $\mathrm{mg} / \mathrm{kg}$, appear to enhance performance (Mangus, B. \& Trowbridge, C., 2005). Caffeine has also been shown to delay fatigue, heighten the feeling of alertness, decrease reaction time, and increase vigilance (Catlin \& Hatton, 1991; Mangus \& Trowbridge, 2005). Spriet, Maclean, Dyck, Hultman, Cederblad, and Graham (1992) reported that a high caffeine dose one hour prior to exercise prolongs exercise due to delaying exhaustion. However, it was reported that caffeine appears to only enhance activities that are endurance activities and not very short-duration, high-intensity exercise bouts (Graham \& Spriet, 1991; Greer, McLean, \& Graham 1998; Spriet, 1995). High levels of caffeine can disqualify an athlete from competition. The NCAA disqualifies athletes who test more than $15 \mu \mathrm{g} / \mathrm{ml}$. Even with this deterrent, caffeine is still used as an ergogenic aid (Mangus \& Trowbridge, 2005). Caffeine levels below the $15 \mu \mathrm{g} / \mathrm{ml}$ will still enhance exercise; therefore it is recommended by Spriet (1995) that caffeine ingestion 48-72 hours prior to exercise be banned. 
Performance-enhancing substances have become of great concern to pediatricians (The American Academy of Pediatrics, 2005). "Efforts to minimize use of performanceenhancing substances require the pediatrician to have an understanding of the incentives for use, a comprehensive definition of performance-enhancing substances, and familiarity with strategies for prevention” (p 1103). The American Academy of Pediatrics released a list of recommendations with regard to the use of performance enhancing substances as part of a policy statement (2005). See Appendix D for the list of recommendations.

Tymowski \& Somerville (2002) report that more than 29\% of New Brunswick, Canada youth females and 30\% of males reported using caffeine to improve sport performance in the 12 months previous to the research. Slightly less than $88 \%$ of the students stated that they had heard of athletes using drugs or doping methods to help them perform better in sport. Youth and adolescents reported they found information about substances used in sport on the tv/radio, in magazines, on the internet, and from coaches, parents, friends and team mates ( Tymowski \& Somerville, 2002; Llorens, 1998). One third of students surveyed reported using caffeine to improve sport, slightly over $41 \%$ of males and slightly less than $39 \%$ of females believe that caffeine could harm their health, or hurt them (Tymowski \& Somerville, 2002) while Llorens (1998) reported that two in five (40.2\%) Quebec youth had taken caffeine in order to improve their athletic performance, but when askedyouth and adolescents reported that they did not know if caffeine would harm their health. In a study by Llorens (1998) through the Drug Awareness Program Royal Canadian Mounted Police, it was reported by The Canadian Centre for Drug Free Sport (1993) in the National School Survey On Drug and Sport that about $30 \%$ of students believed that caffeine would help an athlete perform better.

Students reported that they believed that caffeine would improve their athletic performance and admitted to using caffeine to enhance athletic performance in the last 12 months. (Canadian Centre for Drug-Free Sport, 1993).

Caffeine Intoxication, Caffeinism, and DSM IV-TR Classifications

"Caffeine is the most commonly used mood-altering drug in the world” (Juliano, \& Griffiths, 2005, p403). Many support the DSM IV-TR classification of dependency for caffeine (Gilliland \& Bullock, 1984; Hughes, Oliveto, Liguori, Carpenter, \& Howard, 
1998 ), even though the DSM IV-TR only recognizes caffeine intoxication, caffeine induced anxiety disorder, caffeine induced sleep disorder, and caffeine-related disorder (American Psychiatric Association, 2000).

Caffeine intoxication, previously called Caffeinism (Griffiths, Juliano, \& Chausmer, 2003) can be evident when as little as 100mg of caffeine is consumed per day by those who are unaccustomed to caffeine. To meet the criteria of caffeine intoxication five or more symptoms must develop shortly after consuming caffeine (American Psychiatric Association, 2000). Caffeine intoxication was identified as early as 1914 and was considered to be a state of poisoning not often encountered, but by 1925 multiple cases were reported (McManamy \& Schube, 1936). Caffeinism is defined by Josephson \& Stine (1976) as "a syndrome resulting from the excessive ingestion of caffeine and characterized primarily by cardiovascular and central nervous system manifestations" (pg 776). In a recent study Hughes, Oliveto, Liguori, Carpenter, \& Howard (1998) reported that "a substantial number of current coffee, tea, and soda drinkers endorse criteria for dependence, withdrawal, or intoxication as applied to their caffeine use” (p 105).

The following are current diagnostic criteria for caffeine intoxication as described by the American Psychiatric Association (2000):

\section{Diagnostic criteria for 305.90 Caffeine Intoxication}

A. Recent consumption of caffeine, usually in excess of $250 \mathrm{mg}$ (e.g. more than 2-3 cups of brewed coffee).

B. Five (or more) of the following signs, developing during, or shortly after, caffeine use:

1. restlessness

2. nervousness

3. excitement

4. insomnia

5. flushed face

6. diuresis

7. gastrointestinal disturbance

8. muscle twitching

9. rambling flow of thought and speech

10. tachycardia or cardiac arrhythmia

11. periods of inexhaustibility

12. psychomotor agitation 


\section{Diagnostic criteria for 305.90 Caffeine Intoxication continued}

C. The symptoms in Criterion B cause clinically significant distress or impairment in social, occupational, or other important areas of functioning.

D. The symptoms are not due to a general medical condition and are not better accounted for by another mental disorder (e.g. an Anxiety Disorder).

When symptoms are in excess of those usually associated with caffeine intoxication and when symptoms are sufficiently severe to warrant independent clinical attention the DSM IV-TR recognizes them as Other Caffeine-Induced Disorders (APA, 1994. p. 213). These disorders are categorized as caffeine-induced anxiety and caffeineinduced sleep disorder. The following criteria are diagnostic criteria the DSM IV-TR uses to diagnose each disorder.

\section{Diagnostic criteria for Substance-Induced Anxiety Disorder}

A. Prominent anxiety, Panic Attacks, or obsessions or compulsions predominate in the clinical picture.

B. There is evidence from the history, physical examination, or laboratory findings of either (1) or (2):

1. the symptoms in criterion A developed during, or within 1 month of, substance intoxication or withdrawal.

2. medication use is etiologically related to the disturbance

C. The disturbance is not better accounted for by an anxiety disorder that is not substance induced. Evidence that the symptoms are better accounted for by an anxiety disorder that is not substance induced might include the following: the symptoms precede the onset of the substance use (or medication use); the symptoms persist for a substantial period of time (e.g. about a month) after the cessation of acute withdrawal or sever intoxication or are substantially in excess of what would be expected given the type or amount of the substance used or the duration of the use; or there is other evidence suggesting the existence of an independent non-substanceinduced anxiety disorder (e.g. a history of recurrent non-substance-induced-related episodes).

D. The disturbance does not occur exclusively during the course of a delirium. 


\section{Diagnostic criteria for Substance-Induced Anxiety Disorder continued}

E. The disturbance causes clinically significant distress or impairment in social, occupational, or other important areas of functioning.

Note: This diagnosis should be made instead of a diagnosis of substance intoxication or substance withdrawal only when the anxiety symptoms are in excess of those usually associated with the intoxication or withdrawal syndrome and when the anxiety symptoms are sufficiently sever to warrant independent clinical attention.

Code [Specific Substance] - Induced Anxiety Disorder

(291.8 Alcohol; 292.89 amphetamine (or Amphetamine-Like Substance); 292.89

Caffeine; 292.89 Cannabis; 292.89 Cocaine; 292.89 Hallucinogen; 292.89 Inhalant;

292.89 Phencyclidine (or Phencyclidine-Like Substance); 292.89 Sedative, Hypnotic, or

Anxiolytic; 292.89 Other [or unknown] Substance)

Specify if:

With Generalized Anxiety: if excessive anxiety or worry about a number of events or activities predominates in the clinical presentation.

With Panic Attacks: if Panic Attacks 9see p. 395) predominate in the clinical presentation.

With Obsessive-Compulsive Symptoms: if obsessions or compulsions predominate in the clinical presentation.

With Phobic Symptoms: if phobic symptoms predominate in the clinical presentation.

Specify if (see table on p. 177 for applicability by substance):

With Onset During Intoxication: if the criteria are met for intoxication with the substance and the symptoms develop during the intoxication syndrome

With Onset During Withdrawal: if criteria are met for Withdrawal from the substance and the symptoms develop during, or shortly after, a withdrawal syndrome.

\section{Diagnostic criteria for Substance-Induced Sleep Disorder}

A. A prominent disturbance in sleep that is sufficiently sever to warrant independent clinical attention.

B. There is evidence from the history, physical examination, or laboratory findings of either (1) or (2).

1. the symptoms in Criterion A developed during, or within a month of, Substance Intoxication or Withdrawal.

2. medication use is etiologically related to the sleep disturbance 


\section{Diagnostic criteria for Substance-Induced Sleep Disorder continued}

C. the disturbance is not better accounted for by a Sleep Disorder that is not substance induced. Evidence that the symptoms are better accounted for by a Sleep Disorder tha is not substance induced might include the following: the symptoms precede the onset of the substance use (or medication use); the symptoms persist for a substantial period of time (e.g. about a month) after the cessation of acute withdrawal or sever intoxication, or are substantially in excess of what would be expected given the type or amount of the substance used or the duration of the use; or there is other evidence that suggests the existence of an independent non-substance-induced Sleep Disorder (e.g. a history of recurrent non-substance-related episodes).

D. The disturbance does not occur exclusively during the course of a delirium.

F. the sleep disturbance caused clinically significant distress or impairment in social, occupational, or other important areas of functioning.

Note: this diagnosis should be made instead of a diagnosis of Substance Intoxication or Substance Withdrawal only when the sleep symptoms are in excess of those usually associated with the intoxication or withdrawal syndrome and when the symptoms are sufficiently sever to warrant independent clinical attention.

Code [Specific Substance] - Induced Sleep Disorder

(291.8 Alcohol; 292.89 Amphetamine; 292.89 Caffeine; 292.89 Cannabis; 292.89 Cocaine; 292.89 Opioid; 292.89 Sedative, Hypnotic, or Anxiolytic; 292.89 Other [or unknown] Substance)

\section{Specify if:}

Insomnia Type: if the predominant sleep disturbance is insomnia Hypersomnia Type: if the predominant sleep disturbance is hypersomnia Parasomnia Type: if the predominant sleep disturbance is parasomnia Mixed Type: if more than one sleep disturbance is present and non predominates

\section{Specify if:}

With Onset During Intoxication: if the criteria are met for intoxication with the substance and the symptoms develop during the intoxication syndrome.

With Onset During Withdrawal: if criteria are met for Withdrawal from the substance and the symptoms develop during, or shortly after, a withdrawal syndrome.

Caffeine withdrawal syndrome must be due to the abrupt cessation of, or reduction in, the use of caffeine-containing products (APA, 1994. p 708) Caffeine Withdrawal has been included in the ICD-10 by the World Health Organization (p. 833) 
while the American Psychiatric Association (1994, p. 709) only offers proposed criteria.. The following criteria are criteria given in the DSM-IV for research criteria for caffeine withdrawal.

\section{Research Criteria for caffeine withdrawal}

A. Prolonged daily use of caffeine

Abrupt cessation of caffeine use, or reduction in the amount of caffeine used, closely followed by headache and one (or more) of the following symptoms:

1. Marked fatigue or drowsiness

2. marked anxiety or depression

3. nausea or vomiting

C. The symptoms in Criterion B cause clinically significant distress or impairment in social, occupational, or other important areas of functioning.

D. The symptoms are not due to the direct physiological effects of a general medical condition (e.g. migraine, viral illness) and are not better accounted for by another mental disorder.

Although the DSM-IV stops short of offering diagnostic criteria for caffeine dependence, it has been widely supported in the literature (Bernstein, Carrrol, Thuras, et al, 2002; Griffiths, Juliano, \& Chausmer, 2003; Hering-Hanit \& Gadoth, 2003; Hughes, Oliveto, Liguori, Carpenter, \& Howard, 1998; Juliano \& Griffiths, 2005; Oberstar, Berstein, \& Thuras, 2002; Strain, Mumford, 1994). The American Psychiatric Association (1994) lists the following criteria when diagnosing Substance Dependence (pg. 181) and Substance Abuse (pp. 182-183).

\section{Criteria for Substance Dependence}

A maladaptive pattern of substance use, leading to clinically significant impairment or distress, as manifested by three (or more) of the following, occurring at any time in the same 12-month period:

1. tolerance, as defined by either of the following:

a. a need for markedly increased amounts of the substance to achieve intoxication or desired level.

b. markedly diminished effect with continued use of the same amount of the substrand. 


\section{Criteria for Substance Dependence continued}

2. withdrawal, as manifested by either of the following:

a. the characteristic withdrawal syndrome for the substance (refer to Criteria A and $\mathrm{B}$ of the criteria sets for Withdrawal from the specific substances)

b. the same (or closely related) substance is taken to relieve or avoid withdrawal symptoms.

3. the substance is often taken in larger amounts or over a longer period than was intended

4. There is a persistent desire or unsuccessful efforts to cut down or control substance use

5. A great deal of time is spent in activities necessary to obtain the substance (e.g. visiting multiple doctors or driving long distances), use the substance (e.g. chain smoking), or recover from its effects.

6. Important social, occupational, or recreational activities are given up or reduced because of substance abuse

7. the substance use is continued despite knowledge of having a persistent or recurrent physical or psychological problem that is likely to have been caused or exacerbated by the substance (e.g. current cocaine use despite recognition of cocaine-induced depression, or continued drinking despite that an ulcer was made worse by alcohol consumption)

Specify if:

With Physiological Dependence: evidence of tolerance or withdrawal (i.e. either Item 1 or 2 is present)

Without Phyusiological Dependence: no evidence of tolerance or withdrawal (i.e., neither item 1 or 2 is present)

Course Specifiers (see text for definitions):

Early Full Remission

Early Partial Remission

Sustained Full Remission

Sustained Partial Remission

On Agonist Therapy

In a Controlled Environment

\section{Criteria for Substance Abuse}

A. A maladaptive pattern of use of substance use leading to clinically significant impairment or distress, as manifested by one (or more) of the following, occurring within a 12-month period.

1. Recurrent substance use resulting in a failure to fulfill major role obligations at work, school, or home (e.g. repeated absences or poor work performance related to substance 


\section{Criteria for Substance Abuse continued}

use; substance-related absences, suspensions, or expulsions from school; neglect of children or household)

2. Recurrent substance use in situations in which it is physically hazardous (e.g. driving an automobile or operating a machine when impaired by substance use).

3. Recurrent substance-related legal problems (e.g. arrests for substance-related disorderly conduct).

4. Continued substance use despite having persistent or recurrent effects of the substance (e.g. arguments with spouse about consequences of intoxication, physical fights).

B. the symptoms have never met the criteria for Substance Dependence for this class of substance.

The DSM-IV does not include diagnostic criteria for caffeine dependence due to insufficient information pertaining to other features of dependence (e.g. inability to stop use and use despite harm) which are generally present with other diagnoses of dependence (Griffiths, Juliano, \& Chausmer, 2003).

\section{Summary}

Caffeine is a widely accepted drug in American culture with many adverse affects have been reported in the literature. Among the adverse affects related to caffeine consumption are poor grades and decreased classroom performance (Katholi, Stormer, Stericker, Rankin, Katholi, \& Katholi, 2003), disruption of coordination in complex tasks (Catlin, \& hatton, 1991), agitation, hyperactivity, anxiety, withdrawal from play and interaction, attention disorders, and disruptive behaviors (Dews, 1984; Garattini, 1993), sleep disorders (Bardwell, Ziegler, Ancoli-Israel, Berry, Nelesen, Druning, \& Dimsdale, 2000; Pollak \& Bright, 2003), increased blood pressure, abnormal pulse, trembling, seizures (Catlin \& Hatton, 1991; Zagnoni \& Albano, 2002) allergic reactions (FernandezNieto \& Quirce, 2002), headaches (Hering-Hanit \& Gadoth, 2003), excitement, and nervousness (Zagnoni \& Albano, 2002).

Positive effects of caffeine consumption has shown some benefits. In doses $100 \mathrm{mg}$ and less it has been shown to protect from Alzheimer's disease (Maia \& Mendonca, 2002), improve skin barrier function (Brandner, et al, 2006), decrease auditory reaction time (Barry, et al, 2007), increase frontopolar cortex function 
(Koppelstaetter, et al, 2007), increase driving performance and decrease perception of sleepiness (Biggs, et al, 2007), and increase alertness, improved performance on simple and choice reactive tasks, and increase other cognitive tasks (Brice \& Smith, 2002).

However, with the explosion of the energy drink market, and most of these drinks being high in caffeine content, it is important to understand what people believe about caffeine, how much they are consuming, and what can predict caffeine consumption to avert the negative effects of caffeine.

Copyright (C) Gary Eugene McIlvain 2008 


\section{Chapter 3}

\section{Methodology}

This chapter includes the methodology by which this study was conducted. It will include discussion of the participants, the pilot study conducted, sample selection, procedures, and data analysis.

\section{Participants}

The participants for this study were 300 (approximately 20 subjects per predictor) freshmen at Marshall University in Huntington, WV. All subjects were freshmen, had graduated from high school in the past year, and were 18-20 years of age. Of the 300 participants, $39.3 \%$ were males, $66.7 \%$ were females, and $90 \%$ were Caucasian. More information on the participants is contained in chapter 4.

\section{Instrument}

An anonymous survey was used to determine (1) the amount of caffeine consumed by a sample of freshmen students at Marshall University, (2) their beliefs regarding caffeine consumption, (3) reported perceived benefits and adverse effects of caffeine consumption, (4) reasons for consuming or refraining from consuming caffeine, and (5) predictors of high and low caffeine consumption. Health professionals reviewed the instrument for face validity. Questions 1- 3 were general demographic questions, questions 4-5 were adopted from Hollingshead's Two Factor Index of Social Position in Miller and Salkind (1991 p. 462-469) and found reliable and valid (Ellis, Lane, \& Olesen, 1963; Slomczynski, Miller, \& Kohn, 1981). Questions 6-7 were general demographic and background questions. Question 8 was adopted by permission (via email correspondence with Dr. Palmgreen at the University of Kentucky) from Hoyle, Stephenson, Palmgreen, Lorch, and Donohew (2002 p. 405) and shown to be valid and reliable (Hoyle, et. al, 2002). Questions 9-23 were adapted/adopted with permission (via email correspondence with the Canadian Centre for Drug Free Sport) from Attitudes and behaviors of New Brunswick students towards the use of performance-enhancing 
substances in sport: Final report, 2002, National Survey on Drugs and Sport: Final report by Canadian Centre for Drug-Free Sport, 1993, and Young peoples attitudes towards doping in sport: Final report by the Royal Canadian Mounted Police, 1998. These questions were used to report beliefs and trends. Questions 24-25 were adapted/adopted from the DSM-IV criteria for caffeine induced sleep disorder, intoxication, anxiety disorder, and caffeine related disorder (1994). Questions 26-29 were developed by the investigator to determine the amount of caffeine consumed. See appendix E for a copy of this questionnaire.

\section{Pilot Study}

This questionnaire was utilized in a pilot study by a convenience sample of 30 Marshall University students in the division of Exercise Science, Sport, and Recreation to determine if the questionnaire was understood by university students and to time how long it took for completion of the questionnaire. These participants were not included as subjects in the actual study. Once the participants completed the survey they were asked (1) if they had any questions regarding the survey, (2) if they understood if the question asking the number of drinks of colas they consumed each day over the past week, (3) was anything confusing, and (4) did anything need to be added to the survey. It took participants an average of 15 minutes to take the survey. Changes made to the survey included (1) adding a question on caffeine tablets, gum, and mints due to comments that students use caffeine pills, gum, and/or mints to stay awake when partying on weekends, (2) changing the wording on level of education to include Hollingshead's descriptions of each level of education and putting the choices in order to expedite data entry, (3) and adding the words "soft drinks" after "other" to the beverage consumption chart and the same for energy drinks, and coffee and teas. Socioeconomic status, total caffeine consumption, and milligrams of caffeine per kilogram of body weight per day were calculated to insure a range of scores. After all changes were made, the survey was finalized and the actual version used is contained in Appendix E. 


\section{Sample Selection}

Marshall University UNI 101 (a required university orientation class for all $2000^{+}$ incoming freshmen at Marshall University) and other predominately freshman classes served as the convenience sample. The principal investigator (Gary McIlvain) selected enough class sections to obtain 300 surveys and then contacted course instructors (by looking up course instructors utilizing the course schedule book and online information available to the investigator) and obtained permission to administer surveys in his/her class section(s). Classes used to collect data in were UNI 101 (a freshman orientation class), ENG 101, ENG 102, ESS 118 (Development of Sport and Physical Education in the US), and HS 222 (First Aid). All were classes that generally had high enrollment of freshmen.

\section{Procedures}

Research approval was obtained by a faculty dissertation committee at the University of Kentucky. Next, IRB approval was obtained from the University of Kentucky and then by Marshall University. The dean of each college was contacted to obtain permission to contact individual faculty. Individual class faculty were contacted via email in which the principal investigator (PI) introduced himself and explained the purpose of the study, that it was anonymous, it had IRB approval, and that it should only take 15 minutes to complete. Once permission was granted by the individual class faculty, the PI scheduled a day and time to collect data in each class section. Data were collected in February and took about 2-3 weeks to collect. After introducing himself to the class, the PI emphasized that participation was voluntary and anonymous and would in no way affect the student's grades or credit in the course. Surveys and cover letters (see Appendix E and F) were distributed to each student in the room. All surveys were collected by the PI upon completion. The PI gave all students a survey. If a student did not want to participate (approximately 8-10 in number) or did not meet the inclusion criteria (approximately 50 in number) he/she was instructed to read through the survey if he/she wished and then to return a blank survey when the PI collected all surveys. 


\section{Data Analysis}

Data were coded by hand by the investigator and entered in the computer. SPSS (version 15) was used for all analyses. Socioeconomic status for the participant's father/male guardian and for his/her mother/female guardian was calculated by using Hollingshead's Index of Social Position (Miller \& Salkind, 1991 p. 462). Father's social index was calculated by finding the father's occupation in Hollingshead's categories (categorized by income potential and ranked 1-7, with 1 being the higher score) and then multiplied by a factor weight of 7 to give a partial, or occupation score. Then father's education was ranked 1-7, again with 1 being the highest score one can obtain (meaning a higher SES, the lower the score on Hollingshead's social index, the higher the SES), and multiplied by a factor weight of 4 to obtain a partial, or education score. The scores for occupation and education were added to obtain a social index (the lower the social index total score, the higher the SES). The following shows the comparison of social index to SEs.Mother's SES was tabulated in the same manner. The following is the example given in Miller and Salkind (1991, p 462):

"If one were to compute a score for the manager of a Kroger grocery store who had completed high school and one year of business college, the procedure would be as follows:

Factor Scale Score + Factor Weight $=$ Partial Score

$\begin{array}{llll}\text { Occupation } & 3 & 7 & 21\end{array}$

$\begin{array}{lll}\text { Education } & 3 & 4\end{array}$

Index of Social Position Score 33”

The following shows ranges of Hollingshead's 2 Factor of Social Index:

\begin{tabular}{|l|l|}
\hline Item & Range \\
\hline Occupation & $7-49$ \\
\hline Education & $4-28$ \\
\hline Social Index & $11-77$ \\
\hline
\end{tabular}

The eight items on the Sensation Seeking Scale were scored on a five-point Likert Scale and then summed, resulting in a new variable (called Risky) and that variable had a range of 8-40. Race categories were collapsed and coded as Caucasian or other. Total 
milligrams of caffeine per day were tabulated. Frequencies and percentages were calculated for descriptive analysis. Means and standard deviations were calculated where appropriate. A multiple regression was performed to determine if there were significant predictors of high caffeine consumption. The dependent variable was total caffeine consumption and the predictor variables were sex, sensation seeking, father's social index, mother's social index, ethnicity, participation in organized activities while in high school, participation in organized activities while in college, and a scale consisting of three caffeine beliefs (items of alertness). Correlation analysis was used to determine if there was a relationship between caffeine consumption and sensation seeking. T-tests were used to test hypotheses concerning differences in beliefs and consumption by Sex. Cronbach's alpha and Principal Component Analysis were used to determine intercorrelations between constructs. The Brief Sensation Seeking Scale items, ranges, and calculations were as follows:

\begin{tabular}{|c|c|c|}
\hline Item & Question & Range \\
\hline 1 & I would like to explore strange places & $1-5$ \\
\hline 2 & I get restless when spending too much time at home & $1-5$ \\
\hline 3 & I like to do frightening things & $1-5$ \\
\hline 4 & I like wild parties & $1-5$ \\
\hline 5 & I would like to take off on a trip with no pre-planned routes or timetables & $1-5$ \\
\hline 6 & I prefer friends who are excitingly unpredictable & $1-5$ \\
\hline 7 & I would like to try bungee jumping & $1-5$ \\
\hline 8 & I would love to have new and exciting experiences, even if they are illegal & $1-5$ \\
\hline & $\begin{array}{l}\text { New variable "Risky" was formed by summing the scores of each } \\
\text { individual item. }\end{array}$ & $8-40$ \\
\hline
\end{tabular}

Copyright (c) Gary Eugene McIlvain 2008 


\section{Chapter 4}

Results and Discussion

\section{Results}

Three hundred and three participants were involved in this study. Three surveys were excluded due to excessive missing data or subjects electing not to finish the survey, leaving 300 usable surveys. Of this 300, there were 118 males (39.3\%) and 182 females (60.7\%). Ethnic origin was predominantly Caucasian with 270 (90\%) of participants being Caucasian, 12 (4\%) were African American, five (1.7\%) Hispanic, three (1.0\%) were Asian, and 10 (3.3\%) reported other (see Table 1).

Table 1

Ethnicity of Participants $(N=300)$

\begin{tabular}{|lc|}
\hline Ethnicity & $\mathrm{n}=300$ \\
\hline Male & $118(39.3 \%)$ \\
\hline Female & $182(60.7 \%)$ \\
\hline Caucasian & $270(90.0 \%)$ \\
\hline African American & $5(1.7 \%)$ \\
\hline Hispanic & $3(1.0 \%)$ \\
\hline Asian & $10(3.3 \%)$ \\
\hline Other & $10(3.35)$ \\
\hline
\end{tabular}

Participants’ socioeconomic status was classified using Hollingshead’s Two Factor Index of Social Position (Hollingshead, 1957). Father and mother's occupation and highest level of education were asked. Occupation and level of education were given a numeric value listed in Hollingshead's occupation and education scale. Father's and mothers social index was weighted and tabulated. The lower the social index computation, the higher the socioeconomic status. Means and standard deviations were computed (see Table 2). Reliability was calculated in two ways, first using Cronbach's Alpha of .603, which is acceptable and second by very heavy Principal Component Analysis. All Principal component Analyses were well above .3 suggesting the items 
were closely intercorrelated, indicating that they represented one construct/concept, (see Table 3). Hollingshead's Two Factor Index of Social Position has been found valid and reliable in previous research as well (Ellis, Lane, \& Olesen, 1963; Slomczynski, Miller, \& Kohn, 1981).

Table 2

Social Index

\begin{tabular}{|l|c|c|}
\hline & Mean & Standard Deviation \\
\hline Father's Social Index. dadSI & 40.83 & 17.97 \\
\hline Mother's Social Index. momSI & 39.24 & 16.71 \\
\hline
\end{tabular}

Table 3

Principal Component Analysis for Father's and Mother's Social Index

\begin{tabular}{|l|c|}
\hline \multicolumn{1}{|c|}{ Social Index } & Principal Component Loading \\
\hline Item 1. educationmom & 0.73 \\
\hline Item 2. occupationmom & 0.62 \\
\hline Item 3. occupationdad & 0.76 \\
\hline Item 4. educationdad & 0.83 \\
\hline
\end{tabular}

Among the 300 participants, 255 (85\%) reported participating in organized high school activities (this included activities organized by the high school such as competitive sports, academic competitions, etc., and those activities organized in the community such as boxing, gymnastics, etc.) while 45 (15\%) reported not participating in any organized activity. Eighty-five (28.3\%) of the participants reported participating in organized activities during their freshmen year in college and 215 (71.7\%) reported that they did not participate in any organized activity while in college.

An eight item scale was used to assess sensation seeking. The respondents could choose from 1 -5 on a Likert scale (see Table 4). Means and standard deviations were computed for each of the eight items. The Likert scale scores were totaled (strongly agree $=1$, agree $=2$, neither agree nor disagree $=3$, disagree $=4$, and strongly disagree $=$ 5) to give a numeric value. The range of scores was 8 (lowest possible score) to 40 (highest possible score). The lower the total score, the stronger sensation seeking the respondent was determined to be. Means and standard deviations were computed for each of the eight items of the sensation seeking scale (see Table 5). A variable called 
"Risky" was tabulated by adding together the scores of each of the individual items of the eight item sensation seeking scale. This variable was found reliable in two ways. Cronbach’s Alpha was .741 and there was a heavy Principal Component Analysis. All but one of the eight items of the eight item sensation seeking scale were well above .3, suggesting that the items were closely intercorrelated, and indicating that they represented one construct/concept. When the item that was below .3 was removed from the scale, it increased Cronbach's Alpha slightly, but since the eight item sensation scale has been found valid and reliable in previously published research, all eight items of the scale were included in constructing the variable Risky by summing the responses (see Table 6).

Table 4

Brief Sensation Seeking Scale

\begin{tabular}{|c|c|c|c|c|}
\hline $\begin{array}{c}\text { Strongly Agree } \\
1\end{array}$ & $\begin{array}{c}\text { Agree } \\
2\end{array}$ & $\begin{array}{c}\text { Neither Agree } \\
\text { or Disagree } \\
3\end{array}$ & $\begin{array}{c}\text { Disagree } \\
4\end{array}$ & $\begin{array}{c}\text { Strongly } \\
\text { Disagree } \\
5 \\
5\end{array}$ \\
\hline \multicolumn{5}{|c|}{ Item 1 I would like to explore strange places. } \\
\hline \multicolumn{5}{|c|}{ Item 2 I get restless when spending too much time at home. } \\
\hline \multicolumn{5}{|c|}{ Item 3 I like to do frightening things. } \\
\hline \multicolumn{5}{|c|}{ Item 4 I like wild parties. } \\
\hline \multicolumn{5}{|c|}{ Item 5 I would like to take off on a trip with no pre-planned routes or timetables. } \\
\hline \multicolumn{5}{|c|}{ Item 6 I prefer friends who are excitingly un predicable. } \\
\hline \multicolumn{5}{|c|}{ Item 7 I would like to try bungee jumping. } \\
\hline
\end{tabular}

Table 5

Sensation Seeking Individual Item Descriptives

\begin{tabular}{|l|c|c|}
\hline & Mean & Standard Deviation \\
\hline Item 1 & 2.07 & 0.92 \\
\hline Item 2 & 1.87 & 0.87 \\
\hline Item 3 & 2.89 & 1.08 \\
\hline Item 4 & 3.06 & 1.26 \\
\hline Item 5 & 2.38 & 1.27 \\
\hline Item 6 & 2.50 & 0.93 \\
\hline Item 7 & 2.55 & 1.39 \\
\hline Item 8 & 3.13 & 1.19 \\
\hline Total of Items 1-8. Risky & 20.47 & 5.40 \\
\hline
\end{tabular}


Table 6

Principal Component Analysis for “Risky”

\begin{tabular}{|l|c|}
\hline & $\begin{array}{c}\text { Principal Component } \\
\text { Analysis }\end{array}$ \\
\hline Item 1 & 0.57 \\
\hline Item 2 & 0.18 \\
\hline Item 3 & 0.74 \\
\hline Item 4 & 0.58 \\
\hline Item 5 & 0.69 \\
\hline Item 6 & 0.65 \\
\hline Item 7 & 0.58 \\
\hline Item 8 & 0.66 \\
\hline
\end{tabular}

Fifteen questions were asked in the survey instrument about beliefs and/or reasons to consume or not consume caffeine. Respondents could answer yes or no to these questions. Eight of these questions inquired about beliefs of how caffeine would effect respondents if consumed, one question asked if the respondents had a religious objection to caffeine consumption, and six questions asked how respondents had used caffeine in the past, their daily caffeine consumption, and the number of years the respondents had been consuming caffeine. Frequencies, means, and standard deviations for these questions were computed (see Table 7).

Table 7

Caffeine Beliefs and Use Frequencies

\begin{tabular}{|l|c|c|}
\hline & Yes & No \\
\hline Q1. I believe caffeine will help me concentrate when studying & $\begin{array}{c}83 \\
(27.7 \%)\end{array}$ & $\begin{array}{c}217 \\
(72.3 \%)\end{array}$ \\
\hline Q2. I believe that caffeine will help keep me awake & $\begin{array}{c}229 \\
(76.0 \%)\end{array}$ & $\begin{array}{c}71 \\
(23.7 \%)\end{array}$ \\
\hline Q3. I believe that caffeine will wake me up in the morning & $\begin{array}{c}178 \\
(59.3 \%)\end{array}$ & $\begin{array}{c}122 \\
(40.7 \%)\end{array}$ \\
\hline Q4. I believe that caffeine will help me lose weight & $\begin{array}{c}15 \\
(5.0 \%)\end{array}$ & $\begin{array}{c}285 \\
(95.0 \%)\end{array}$ \\
\hline $\begin{array}{l}\text { Q5. I believe caffeine enhances performance (athletic, academic, } \\
\text { artistic, etc) }\end{array}$ & $\begin{array}{c}57 \\
(19.0 \%)\end{array}$ & $\begin{array}{c}243 \\
(81.0 \%)\end{array}$ \\
\hline $\begin{array}{l}\text { Q6. I believe that caffeine can be harmful to my health and can } \\
\text { hurt me }\end{array}$ & 239 & 61 \\
\end{tabular}




\begin{tabular}{|c|c|c|}
\hline Q7. I believe that caffeine is addictive & $\begin{array}{c}247 \\
(82.3 \%)\end{array}$ & $\begin{array}{c}53 \\
(17.7 \%) \\
\end{array}$ \\
\hline \multicolumn{3}{|l|}{ Table 7 Continued } \\
\hline Q8. I believe that caffeine can disrupt coordination & $\begin{array}{c}129 \\
(43.0 \%)\end{array}$ & $\begin{array}{c}171 \\
(57.0 \%)\end{array}$ \\
\hline Q9. I have religious objections to caffeine consumption & $\begin{array}{c}4 \\
(1.3 \%)\end{array}$ & $\begin{array}{c}296 \\
(98.7 \%)\end{array}$ \\
\hline Q10. Have you ever used caffeine to wake up in the morning & $\begin{array}{c}182 \\
(60.7 \%)\end{array}$ & $\begin{array}{c}118 \\
(39.3 \%)\end{array}$ \\
\hline Q11. Have you ever used caffeine to stay awake & $\begin{array}{c}229 \\
(76.3 \%)\end{array}$ & $\begin{array}{c}71 \\
(23.7 \%)\end{array}$ \\
\hline $\begin{array}{l}\text { Q12. Have you ever used caffeine to enhance physical } \\
\text { performance }\end{array}$ & $\begin{array}{c}41 \\
(13.7 \%)\end{array}$ & $\begin{array}{c}259 \\
(86.3 \%)\end{array}$ \\
\hline $\begin{array}{l}\text { Q13. Have you ever used caffeine to enhance mental } \\
\text { performance }\end{array}$ & $\begin{array}{c}80 \\
(26.7 \%) \\
\end{array}$ & $\begin{array}{c}220 \\
(73.3 \%) \\
\end{array}$ \\
\hline $\begin{array}{l}\text { Q14. Have you ever used drinks/pills with caffeine to lose } \\
\text { weight }\end{array}$ & $\begin{array}{c}26 \\
(8.7 \%) \\
\end{array}$ & $\begin{array}{c}274 \\
(91.3 \%) \\
\end{array}$ \\
\hline $\begin{array}{l}\text { Q15. Do you drink beverages with caffeine in them on a daily } \\
\text { basis? }\end{array}$ & $\begin{array}{c}195 \\
(65.0 \%)\end{array}$ & $\begin{array}{c}105 \\
(35.0 \%)\end{array}$ \\
\hline & Mean & $\begin{array}{l}\text { Standard } \\
\text { Deviation }\end{array}$ \\
\hline 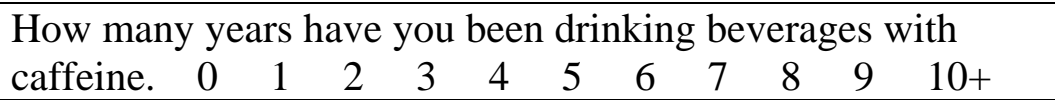 & 9.11 & 2.09 \\
\hline
\end{tabular}

Participants were asked if they had signs and/or symptoms of caffeine intoxication or if they had signs and/or symptoms of caffeine withdrawal. Respondents checked all signs/symptoms of caffeine intoxication and/or withdrawal they had experienced. Responses were tabulated as yes or no answers (if subjects checked a sign/symptom then it was recorded as yes and if left unchecked then it was recorded as no). The total number of signs/symptoms for each respondent was computed by adding the totaling the number of yes responses for intoxication and withdrawal. Eighty three percent reported having at least one sign/symptom of caffeine intoxication in the past while 51\% reported having at least one sign/symptom of caffeine withdrawal. Of the 22 signs/symptoms of caffeine intoxication, the maximum number any one person reported was 14 . Of nine signs/symptoms of caffeine withdrawal, the maximum number any one 
person reported was eight. Frequencies, means, and standard deviations caffeine intoxication and withdrawal were computed (see Table 8).

Table 8

Caffeine Intoxication and Withdrawal Frequencies, Percentages, and Means

\begin{tabular}{|c|c|c|}
\hline Caffeine Intoxication & Yes & No \\
\hline Item 1 restlessness & $120(40.0 \%)$ & $180(60.0 \%)$ \\
\hline Item 2 excitement & $115(38.3 \%)$ & 185 (61.7\%) \\
\hline Item 3 hot flashes & $13(4.3 \%)$ & $287(95.7 \%)$ \\
\hline Item 4 nervousness & $35(11.7 \%)$ & $265(88.3 \%)$ \\
\hline Item 5 can’t sleep & $147(49.0 \%)$ & $153(51.0 \%)$ \\
\hline Item 6 red faced & $7(2.3 \%)$ & $293(97.7 \%)$ \\
\hline Item 7 frequent urination & $96(32.0 \%)$ & $204(68.0 \%)$ \\
\hline Item 8 stomach pain & $49(16.3 \%)$ & $251(83.7 \%)$ \\
\hline Item 9 muscle twitching & $39(13.0 \%)$ & $261(87.0 \%)$ \\
\hline Item 10 rambling speech & $24(8.0 \%)$ & 276 (92.0\%) \\
\hline Item 11 can’t concentrate & $43(14.3)$ & 257 (85.7\%) \\
\hline Item 12 fast heart beat & $52(17.3 \%)$ & $248(82.7 \%)$ \\
\hline Item 13 hives & $0 \quad(0.0 \%)$ & 300 (100.0\%) \\
\hline Item 14 irritated & $23 \quad(7.7 \%)$ & 277 (92.3\%) \\
\hline Item 15 rash & $0 \quad(0.0 \%)$ & $300(100.0 \%)$ \\
\hline Item 16 panic attack & $11(3.7 \%)$ & $289(96.3 \%)$ \\
\hline Item 17 anxiety & $37(12.3 \%)$ & $263(87.7 \%)$ \\
\hline Item 18 obsessive & $8 \quad(2.7 \%)$ & $292(97.3 \%)$ \\
\hline Item 19 compulsive & $12(4.0 \%)$ & 288 (96.0\%) \\
\hline Item 20 headache & $94(31.3 \%)$ & 206 (68.7\%) \\
\hline Item 21 irregular heart beat & $27 \quad(9.0 \%)$ & $273(91.0 \%)$ \\
\hline Item 22 hyperactivity & $69(23.0 \%)$ & $231(77.0 \%)$ \\
\hline Caffeine Withdrawal & Yes & No \\
\hline Item 1 fatigue & $61(20.3 \%)$ & 239 (79.7\%) \\
\hline Item 2 drowsiness & $45(15.0 \%)$ & $255(85.0 \%)$ \\
\hline Item 3 anxiety & $7(2.3 \%)$ & $293(97.7 \%)$ \\
\hline Item 4 depressed & $13(4.3 \%)$ & 287 (95.7\%) \\
\hline Item 5 sick at stomach & $11(3.7 \%)$ & 289 (96.3\%) \\
\hline Item 6 vomiting & $2(0.7 \%)$ & 298 (99.3\%) \\
\hline Item 7 headache & $108(36.0 \%)$ & $192(64.0 \%)$ \\
\hline Item 8 cravings & $74(24.7 \%)$ & 226 (75.3\%) \\
\hline Item 9 irritability & $41(13.7 \%)$ & $259(86.3 \%)$ \\
\hline & Mean & Standard Deviation \\
\hline
\end{tabular}




\begin{tabular}{|l|l|l|}
\hline Total Intoxication Signs/Symptoms & 3.40 & 2.99 \\
\hline Total Withdrawal Signs/Symptoms & 1.20 & 1.59 \\
\hline
\end{tabular}

Finally, the total amount of caffeine consumed/ingested was computed by asking participants to complete charts indicating how much caffeine each respondent consumed in soft drinks, energy drinks, coffee and tea, and caffeine pills, gum, and/or mints.

Drinks were asked by size of drink and number of drinks consumed. Caffeine pills, gum, and/or mints were asked by number of days consumed and number of pills, gum, and/or mints consumed each day. Having few respondents indicating they consumed caffeine pills, gum, and/or mints, this category was only used for tabulating total milligrams of caffeine used. Total caffeine was tabulated and means and standard deviations were computed (See Table 9).

Table 9

Total Caffeine Means and Standard Deviations

\begin{tabular}{|c|c|c|}
\hline & Mean & Std Deviation \\
\hline Item 1 Milligrams of Caffeine/Day. *totalcaffein & 849.86 & 1265.62 \\
\hline Natural log of totalcaffein. *lncaff & 9.44 & 5.88 \\
\hline $\begin{array}{l}\text { Item } 2 \text { Milligrams of Caffeine/Kilogram of Body } \\
\text { Weight/Day. *mgkgday }\end{array}$ & 12.08 & 18.43 \\
\hline $\begin{array}{l}\text { Number that reported they did not consume caffeine in the } \\
\text { reporting time frame of the previous two weeks }\end{array}$ & \multicolumn{2}{|c|}{$16(5.33 \%)$} \\
\hline
\end{tabular}

* coding used in SPSS spreadsheet

To look for predictors of high and low caffeine consumption, a regression analysis was performed. Since the dependant variable (total caffeine) was sharply skewed to the right, its variability was tightly constrained. To remedy this, all the values of the dependent variable were expressed in natural logarithms as recommended by a statistics expert. (That process approximately normalized the distribution making it more informative.) (See Table 9). Questions 1-3 of caffeine beliefs construct a scale of beliefs of caffeine effect that we called three items for concentration, keep awake, and wake. This scale was found reliable in two ways. First the loadings of Principal Component Analysis were all large and well above .3 suggesting the items were closely intercorrelated, indicating that they represent one construct/concept and second by a 
Cronbach’s Alpha of .601 (a .601 Cronbach’s Alpha is an artifact of the small number of items that make up the scale). This collection of items was a powerful predictor of caffeine consumption (see Table 10).

Table 10

Three items for concentration, keep awake, and wake up

\begin{tabular}{|l|c|}
\hline & Principal Component Loading \\
\hline Item 1 Belief Question 1 & .61 \\
\hline Item 2 Belief Question 2 & .79 \\
\hline Item 3 Belief Question 3 & .81 \\
\hline
\end{tabular}

When the regression analysis was computed, father's social index, participation in organized activity in college, and three items for concentration, keep awake, and wake up (items of alertness) were statistically significant. On average, every time the respondent's father's social index increased by one point, caffeine consumption increased on average by eight percent. Respondents that indicated they participated in organized activity while in college consumed on average $60.7 \%$ more caffeine than those who indicated they did not participate in organized activity while in college. It was also found that every time the three items for concentration, keep awake, and wake up increased one point, caffeine consumption increased on average 41.1\%. Sex, sensation seeking, mother's social index, ethnicity, and participation in an organized activity in high school were not statistically significant. A total of the 8 items of the sensation seeking scale was used (Risky) and since the ethnic background was Caucasian, ethnicity was tabulated as a new variable race (which computed race to either Caucasian or Other, with Other being a summation of African American, Asian, Hispanic, and Other) (see Table 11). The regression analysis had a Cronbach’s Alpha of .741

Table 11

Regression Analysis to Predict Caffeine Consumption

\begin{tabular}{|l|l|}
\hline & \multicolumn{1}{|c|}{ Sig } \\
\hline Item 1 Sex & 0.19 \\
\hline Item 2 Sensation Seeking & 0.16 \\
\hline Item 3 Father's Social Index. & $0.02^{*}$ \\
\hline Item 4 Mother's Social Index & 0.66 \\
\hline Item 5 Ethnicity & 0.31 \\
\hline
\end{tabular}




\begin{tabular}{|l|l|}
\hline Item 6 Participation in Organized High School Activity & 0.74 \\
\hline Item 7 Participation in Organized College Activity & $0.01^{*}$ \\
\hline $\begin{array}{l}\text { Item 8 Questions 1-3 of Caffeine Beliefs. Three items for concentration, keep } \\
\text { awake, wake up }\end{array}$ & $0.00^{* * *}$ \\
\hline
\end{tabular}

$* \mathrm{p}<.05 \quad * * \mathrm{p}<.01 \quad * * * \mathrm{p}<.001$

When analyzing belief questions one through eight for Sex differences, only one question was found significant, which was belief question 7 (I believe caffeine is addictive). Females were more likely to believe that caffeine is addictive than their male counterparts. Independent t-tests were computed and significance levels reported (see Table 12). A correlation analysis showed no statistical relationship between the BSSS variable Risky and total caffeine consumption or between the Brief Sensation Seeking Scale variable Risky and the natural logarithm of total caffeine consumption (see Table 13).

Table 12

T-tests for Sex Differences on Caffeine Beliefs

\begin{tabular}{|l|c|c|}
\hline Caffeine Belief Question & t & Significance \\
\hline 1. concentrate & 1.11 & 0.26 \\
\hline 2. keepawake & 0.84 & 0.40 \\
\hline 3. wakeup & 1.67 & 0.09 \\
\hline 4. losewght & -0.57 & 0.56 \\
\hline 5. perforamc & -0.13 & 0.18 \\
\hline 6. harmful & 1.43 & 0.15 \\
\hline 7. addictive & 2.13 & $0.03^{*}$ \\
\hline 8. coordinate & 1.13 & 0.25 \\
\hline
\end{tabular}

$* \mathrm{p}<.05$

$* * \mathrm{p}<.01$

$* * * \mathrm{p}<.001$

Table 13

BSSS and Total Caffeine/Natural Log of Total Caffeine Correlation

\begin{tabular}{|c|c|c|}
\hline & totalcaffeine & lncaff \\
\hline Risky & 0.24 & 0.20 \\
\hline
\end{tabular}




\section{Discussion}

Research Questions were (1) what is the average amount of caffeine consumed daily, (2) what beliefs do these college students have regarding caffeine (e.g. effects on health, performance enhancement, weight loss aid, and aid in staying awake or alert), (3) what are the perceived health benefits and adverse health effects of caffeine consumption, (4) what reasons do students give for either consuming or not consuming caffeine, and (5) are there predictors of high and low caffeine consumption (e.g. SES, sex, sensation seeking, and participation in sport, band, academic or other extracurricular activities)?

Hypotheses for this research were (1) more than 50\% of students will report having experienced at least one adverse health effects (intoxication or withdrawal signs/symptoms) due to caffeine consumption, (2) sensation seeking will be a predictor of caffeine consumption, and (3) a linear composite of the following will predict caffeine consumption: Sex, SES, beliefs, and sensation seeking.

The first research question was, "What is the amount of caffeine consumed daily?” The recommended maximum amount of caffeine consumption per kilogram per day was exceeded. Health Canada reported that excess of $2.5 \mathrm{mg} / \mathrm{kg} /$ day can cause adverse health effects. Kuchment (2007) reported that Roland Griffiths stated that moderate doses of 200-300mg/day of caffeine were not harmful. Griffith's doses are supported by The Mayo Clinic (2007). Respondents to the present survey may not be aware of the total amount of caffeine they are consuming because they do not pay close enough attention to product labels and may not know other names caffeine can be listed under on the product labeling. Statements from participants after they finished the survey such as "I didn't realize a lot of the stuff I was drinking had caffeine in it" and "I was drinking that because caffeine was not listed on the label," lead the researcher to believe that labeling on drinks are inconsistent and misleading to consumers. The mean milligram of caffeine consumed per day in the present study was 849.86, which computes 
to $12.08 \mathrm{mg} / \mathrm{kg} /$ day. This is nearly five times the recommended amount of Health Canada and approximately three times the recommended amount by Griffiths and The Mayo Clinic. This level of caffeine consumption is generally associated with signs and symptoms of caffeine intoxication and withdrawal if one quits consuming caffeine. Signs and symptoms of intoxication (caffeine poisoning) can include restlessness, excitement, hot flashes, nervousness, sleeplessness, flushed face, frequent urination, stomach pain, muscle twitching, rambling speech, lack of concentration, fast heart rate, hives, feeling irritated, rash, panic attach, anxiety, feeling obsessive or compulsive, headache, irregular heart beat, hyperactive. Signs and symptoms of caffeine withdrawal can include fatigue, drowsiness, anxiety, depression, feeling sick at stomach, vomiting, headache, cravings for caffeine, and irritability.

The second research question related to beliefs of college students regarding caffeine. These beliefs concerning whether caffeine has positive and/or negative health effects were somewhat inconsistent. Just more than $72 \%$ of respondents did not believe that caffeine would help them concentrate while $76 \%$ and slightly more than $59 \%$ believed that caffeine will keep them awake or wake them up in the morning respectively. When these three beliefs were summed and used as a scale it was found to be a very strong predictor of high caffeine consumption. This supports Pela (1989), in that the drinks are sought out due to their caffeine content and supports Kristiansen, Levy-Milne, Barr, and Flint (2005) findings that caffeine was sought after to counteract tiredness. More than $81 \%$ of the respondents did not believe that caffeine would enhance athletic, academic, artistic, or other performances. This finding would suggest that respondents would not seek drinks with caffeine in them due to not believing these drinks do not enhance performance. This is a different finding than that of Kristiansen, et al (2005) who reported that caffeine was sought by those wanting to enhance performance and have more energy. Belief questions that caffeine can harm one's health, it is addictive, and it can disrupt coordination were also somewhat inconsistent. Nearly $80 \%$ of respondents reported that they believe caffeine can be harmful and hurt them while and a very similar percentage (82\%) said it is addictive. Fifty-seven percent of respondents reported that they believe that caffeine can disrupt coordination. Even with such a large 
number of respondents reporting that they believe caffeine has negative health effects and is addictive it was found that they still exceeded about 4-6 times the recommended maximum amount of caffeine. This suggests that even though respondents felt that caffeine has negative health effects, the desire to use caffeine to stay awake or to wake up in the morning takes precedence in their decision making process of whether or not to use caffeine. Sex was only significant in the belief that females were more likely than males to believe caffeine was addictive.

The third research question was concerned with the perceived health benefits and adverse health effects of caffeine consumption. It was found that $83 \%$ of the respondents reported having at least one sign/symptom of caffeine intoxication and respondents had a mean of 3.4 signs/symptoms. This is slightly lower than the DSM IV-TR diagnostic criteria of 5 or more signs/symptoms to diagnose someone with caffeine intoxication. Even though the DSM IV-TR stops short of offering diagnostic criteria for caffeine withdrawal, the notion of withdrawal is supported by many authors (Bernstein, Carrrol, Thuras, et al, 2002; Griffiths, Juliano, \& Chausmer, 2003; Hering-Hanit \& Gadoth, 2003; Hughes, Oliveto, Liguori, Carpenter, \& Howard, 1998; Juliano \& Griffiths, 2005; Oberstar, Berstein, \& Thuras, 2002; Strain, Mumford, Silverman, et al, 1994). The present study found that $51 \%$ of respondents reported having at least one sign/symptom of caffeine withdrawal. This percentage could be due to the fact that $65 \%$ of respondents reported drinking caffeine on a daily basis for a mean of more than 9 years, thus reinforcing caffeine dependence and averting withdrawal. Signs and symptoms of withdrawal would not occur if caffeine were constantly consumed, thus giving a very high percentage reporting that they have had signs/symptoms of caffeine intoxication (83\%), while only 51\% reported withdrawal signs/symptoms.

Research question number four related to reasons participants gave for consuming or not consuming caffeine. Sixty-five percent of respondents reported consuming caffeine on a daily basis for a mean of nine years. Almost $61 \%$ had used caffeine to wake up in the morning while $76.3 \%$ had used caffeine to stay awake. Only $13.7 \%$ of subjects reported using caffeine to enhance physical performance and 26.7\% reported using caffeine to enhance mental performance. A mere $8.7 \%$ of respondents reported 
using caffeine to lose weight. This suggests that participants in this study consumed caffeine for specific reasons, which were to help them wake up and to help them stay awake. By in large, caffeine was not consumed by participants of this study to enhance physical or mental performance or to lose weight.

Predictors of caffeine consumption were addressed in the fifth research question. Even though there were no predictors of low caffeine consumption, high caffeine consumption predictors were found. Father's social index, participation in organized activities (athletics, intramurals, and other organized activities on and/or off campus) while in college, and a scale called three items for concentration, keep awake, and wake up were statistically significant in predicting caffeine consumption. As the father's social index increased (thus SES decreasing) it was found that caffeine consumption increased. Drinks that were consumed in the largest quantities were soft drinks, tea, and brewed coffee (other than Starbucks coffee). This may be a fact that these drinks are less expensive thus being more available to families of lower SES. Participation in organized college activity was found to be a significant predicator of caffeine consumption. This supported Miller's (2008) findings that energy drinks (caffeinated drinks) were associated with those that had a self reported jock identity. Where in the present study, it was found that more common drinks containing caffeine were consumed more than energy drinks, but were consumed significantly higher by those that associated themselves with activity, such as those Miller reported with jock identity.

The researcher did not expect father's social index to impact caffeine consumption and mother's social index would not (see Table 13). With social index using occupation and highest education achieved, mothers/female guardians had a slightly higher social index than did the fathers/male guardians. Father's/male guardian's social index was found to be a significant predictor of caffeine consumption. As father's/male guardian's social index increased (SES decreasing with increasing social index) caffeine consumption increased. This could be in part due to the cheaper costs of drinks with caffeine in them (e.g. soft drinks, tea, coffee) making them more affordable to those with less disposable income. 
Table 13

Hollingshead's Index of Social Position Classification Descriptions

\begin{tabular}{|c|c|}
\hline \multicolumn{2}{|c|}{ Hollingshead's Index of Social Position } \\
\hline Description & Range of Scores \\
\hline Upper & $11-17$ \\
\hline Upper-Middle & $18-31$ \\
\hline Middle & $32-47$ \\
\hline Lower-Middle & $48-63$ \\
\hline Lower & $64-77$ \\
\hline
\end{tabular}

Sensation seeking was not found to be statistically significant in predicting caffeine consumption. This differs from what Miller (2008) and Gurpegui, et al (2007) reported. This may be due to the population of the study. Marshall University freshmen were probably not motivated by sensation seeking ads and may have been deterred by the cost of the energy drinks. They also seemed to be using caffeine in order to stay awake and to wake up in the mornings rather than to seek a new experience. Even though participation in organized activity while in college was found a significant predictor of increased caffeine consumption, the participants were not found to be sensation seekers. If athletes alone were participants on a broader scale, sensation may have been found a significant predictor of caffeine consumption.

Even though 85\% of respondents reported participating in organized activities while in high school and only slightly more than 28\% reported participating in organized activity while in college, participation in organized activity while in college were not significantly related to caffeine consumption. Participation in organized activities while in high school was not significant on caffeine consumption. This could be due to the respondents being busier in college than they were while in high school and using coffee or caffeine drinks to wake up or give them energy for the activities, or this result could be due to the fact that they were making buying decisions now that they were in college instead of a parent/guardian buying beverages for them.

Beliefs about alertness were found to be a strong predictor of high caffeine consumption. This was expected by the researcher and supports findings by Kristiansen, et al (2005) that college athletes consume caffeine to counteract tiredness. With $76 \%$ of 
respondents believing that caffeine would help keep them awake and slightly more than $59 \%$ of respondents believing that caffeine would wake them up in the morning, this again suggests that college freshmen sought out drinks with caffeine in them to either keep them up or to wake them up.

The hypothesis that more than $50 \%$ of respondents will report having experienced at least one adverse health effect due to caffeine was accepted while the hypothesis that sensation seeking would be a predictor of caffeine consumption was rejected. The hypothesis that a linear composite of Sex, SES, beliefs, and sensation seeking would predict caffeine consumption was partially accepted since father's SES, beliefs about alertness, and participation in organized activity while in college were significant predictors, although sensation seeking was not.

\section{Limitations}

Limitations existed within this study. When determining SES, only fathers/male guardian and mother/female guardian's social index was calculated. Students were not asked their individual occupation and/or educational level. This was due to students being traditional college freshmen, or college freshmen that have graduated from high school within the past year when data collected. It was believed that the primary SES would come from the parents social index, thus the participants social index was not calculated.

Another limitation relates to the location where the study was conducted. Only students at Marshall University were used as participants thus limiting generalization. Marshall University is a mid-sized college that is predominately Caucasian and located in Appalachia. Being in Appalachia in West Virginia made Marshall University unique in that it had a very large number of first time college students, meaning that a large number of participants were likely to be the first in their family to attend college.

Other limitations were that the data were self reported, thus it may not be as accurate if participants were asked to track caffeine consumption over a period of two weeks. When asked how much of certain beverages, pills, gum, etc that contains caffeine, participants had to rely on memory, thus it could have affected actual results. In addition a question was never asked if someone had never consumed any caffeine, which 
could have affected mean caffeine consumption. It was asked "what is the average number of each drink you have consumed each day over the past two weeks.” If a person marked zero, it did not mean that they had never consumed caffeine, just not over the past two weeks.

Copyright @ Gary Eugene McIlvain 2008 


\section{Chapter 5}

Summary, Conclusions, and Implications

\section{Summary}

The purpose of this study was to determine (1) the amount of caffeine consumed by a sample of freshmen students at Marshall University, (2) their beliefs regarding caffeine consumption, (3) reported perceived benefits and adverse effects of caffeine consumption, (4) reasons for consuming or refraining from consuming caffeine, and (5) predictors of high and low caffeine consumption. These data will give health promotion professionals information which will be useful in planning interventions.

A pilot study was conducted to refine the instrument. The survey was then administered to 300 freshmen students at Marshall University who were enrolled in undergraduate classes and who had graduated from high school in the past year. Descriptive statistics were computed. Correlations, t-tests and a multiple regression were used to test the hypotheses. Eighty-three percent of subjects reported having at least one sign/symptom of caffeine intoxication in the past while 51\% reported having at least one sign/symptom of caffeine withdrawal. The mean milligram of caffeine consumed per day in the present study was 849.86 , which computes to $12.08 \mathrm{mg} / \mathrm{kg} / \mathrm{day}$. This was 3 to 5 times the recommended amount. A multiple regression was computed to determine predictors of caffeine consumption. Father's social index, participation in organized activity in college, and three items for concentration, keep awake, and wake up (items of alertness) were statistically significant. On average, every time the respondent's father's social index increased by one point, caffeine consumption increased on average by eight percent. Respondents who participated in organized activity while in college consumed on average $60.7 \%$ more caffeine than those who indicated they did not participate in organized activity while in college. Every time the three items for concentration, keep awake, and wake up increased one point, caffeine consumption increased on average 41.1\%. Females were more likely to believe that caffeine is addictive than their male counterparts. A correlation analysis showed no statistical relationship between the brief sensation-seeking scale (BSSS) variable Risky and total caffeine consumption or between the BSSS variable Risky and the natural logarithm of total caffeine consumption. 
Caffeine users represented all social and demographic characteristics that were included in the data collection. High caffeine users, greater than 200mg/day, are typical of the population studied. 


\section{Conclusions}

1. The average amount of caffeine consumed by participants in this study was $12.08 \mathrm{mg} / \mathrm{kg} /$ day which was 3 to 5 times the recommended amount. College freshmen are drinking caffeine at levels that would trigger withdrawal if they ever stopped using it (which they have not done). They may not be aware of the total amount they are consuming due to not paying attention to labeling, not calculating it, not caring, or possibly by not knowing how much caffeine is too much. While some caffeine may be permissible, caffeine in large quantities may have health consequences.

2. When asked, $76 \%$ of students believed that caffeine would help keep them awake and 59.3\% believed it would wake them up in the morning. Slightly more than $79 \%$ of students believed that caffeine can be harmful to their health and $82.3 \%$ believed that caffeine is addictive. Students seemed to seek out caffeine for specific purposes even though they believed it could be harmful to their health and was addictive. Only $19 \%$ of students believed that caffeine can help performance (athletic, academic, artistic, etc).

3. There were no perceived health benefits to consuming caffeine. Only $27.7 \%$ of students believed that caffeine would help them concentrate when studying and only five percent believed that caffeine would help them lose weight. Forty-three percent of students believed that caffeine would disrupt coordination. As discussed in \#2, most students believed that caffeine was addictive and could harm them, but when asked, they did not believe it helped with weight loss, concentration, or that caffeine could disrupt coordination.

4. The two main reasons students gave for consuming caffeine was to wake up in the morning and to stay awake. Slightly more than $60 \%$ of students reported using caffeine to wake up in the morning while more than $76 \%$ of students reported using caffeine to stay awake. This is consistent with the belief that caffeine would wake them up and keep them awake. Only $13.7 \%$ of the students reported using caffeine to enhance physical performance while $26.7 \%$ reported using caffeine to enhance mental performance. This is consistent with the reported beliefs of caffeine helping with concentration and performance (with $19 \%$ of students believing that caffeine would help 
with performance and $27.7 \%$ believing that caffeine would help them concentrate). Students stated that they were drinking caffeine for the purpose of waking up or staying awake, but the level of consumption was much higher than necessary to achieve that purpose.

5. There were three significant predictors of high caffeine consumption and no predictors of low caffeine consumption. Predictors of high caffeine consumption were father's social index, participation in organized activity in college, and three items for concentration, keep awake, and wake up (items of alertness). 


\section{Implications}

Future research concerning caffeine beliefs and consumption patterns should be expanded to include middle school, high school, trade schools, junior colleges, community colleges, military, traditional college/universities (including freshmen through graduate students), college/university faculty and military officers. This would give a broader view of beliefs and consumption patterns to help the health professional determine when these beliefs and consumption patterns are developed and how they change over time. Investigating caffeine consumption among trade schools, junior colleges, community colleges and the military, researchers would allow researchers to include a larger concentration of low SES participants in their population. Another area of research would be to expand the questions regarding beliefs about caffeine. This could include more belief questions of harmful and beneficial health effects due to caffeine consumption. Investigating student athletes in college, high school, and middle school settings might allow for a better assessment of sensation seeking and caffeine consumption. Another area of research with regard to caffeine consumption is the current trend of mixing caffeine with alcohol. This seems to be a growing in popularity among college students and was not specifically addressed in this study.

While knowledge might not be sufficient for changing behavior, some knowledge is needed and these students appeared to be lacking some important information about caffeine. When teaching health classes in high school or college, teachers and college health professionals should include teaching health effects of caffeine as they do fat intake and alcohol consumption. Some of the topics that should be included are: how to read labels and calculate daily caffeine consumption, what other foods or substances contain caffeine (e.g. guarana), health effects of caffeine (both positive and negative), how much caffeine is too much, and the amount of caffeine necessary to wake up and to keep one awake. This information would enable students to make better decisions on how much caffeine (if any) to consume.

Another implication of this study is to encourage the CDC to include questions regarding caffeine consumption on the Youth Risk Behavior Surveillance Survey. It was reported that the freshmen respondents, ranging from age 18-20, have consumed caffeine 
for a mean of 9.11 years. This shows that they were consuming caffeine by the age of 911 years of age and possibly before. Attitudes and behaviors of New Brunswick students towards the use of performance-enhancing substances in sport: Final report, 2002, National Survey on Drugs and Sport: Final report by Canadian Centre for Drug-Free Sport, 1993, and Young peoples attitudes towards doping in sport: Final report by the Royal Canadian Mounted Police, 1998 both asked questions regarding caffeine consumption along with asking use of tobacco, alcohol, marijuana, steroids, and other drugs. This could lead to longitudinal data of caffeine consumption patterns, reasons caffeine is consumed; how that changes as one gets older; and the number of signs/symptoms of caffeine intoxication and withdrawal reported at different ages.

With more than $78 \%$ of the respondents consuming more than the recommended amount (200/mg of caffeine per day), experts may not appreciate the heavy use of caffeine among the population at large. What quantifies high caffeine consumption should re-evaluated by health professionals to better determine categories of consumption.

Copyright @ Gary Eugene McIlvain 2008 
Appendix A

\section{Zuckerman’s Sensation Seeking Scale (1979 p. 268-296)}

1. A. I like "wild uninhibited parties.

B. I prefer quiet parties with good conversations.

2. A. There are some movies I enjoy seeing a second or even a third time.

B. I can't stand watching a movie that I've seen before.

3. A. I often wish I could be a mountain climber.

B. I can’t understand people who risk their necks climbing mountains.

4. A. I dislike all body odors.

B. I like some of the earthy body smells.

5. A. I get bored seeing the same old faces.

B. I like the comfortable familiarity of everyday friends.

6. A. I like to explore a strange city or section of a town by myself, even if it means getting lost.

B. I prefer a guide when I am in a place I don't know well.

7. A. I dislike people who do or say things just to shock or upset others.

B. When you can predict almost everything a person will do and say he or she must be a bore.

8. A. I usually don't enjoy a movie or play where I can predict what will happen in advance.

B. I don't mind watching a movie or play where I can predict what will happen in advance.

9. A. I have tried marijuana or would like to.

B. I would never smoke marijuana.

10. A. I would not like to try any drug which might produce strange and dangerous effects on me.

B. I would like to try some of the new drugs that produce hallucinations.

11. A. A sensible person avoids activities that are dangerous.

B. I sometimes like to do things that re a little frightening.

12. A. I dislike "swingers."

B. I enjoy the company of real "swingers."

13. A. I find that stimulants make me uncomfortable.

B. I often like to get high (drinking liquor or smoking marijuana).

14. A. I like to try new foods that I have never tasted before.

B. I order the dishes with which I am familiar, so as to avoid disappointment and unpleasantness.

15. A. I enjoy looking at home movies or travel slides.

B. Looking at someone's home movies or travel slides bores me tremendously.

16. A. I would like to take up the sport of water-skiing.

B. I would not like to take up water-skiing.

17. A. I would like to try surf-board riding.

B. I would not like to try surf-board riding. 
18. A. I would like to take off on a trip with no pre-planned or definite routes, or timetable.

B. When I go on a trip I like to plan my route and timetable fairly carefully.

19. A. I prefer the "down-to-earth" kinds of people as friends.

B. I would like to make friends in some of the "far-out" groups like artists or "hippies."

20. A. I would not like to learn to fly an airplane.

B. I would like to learn to fly an airplane.

21. A. I prefer the surface of the water to the depths.

B. I would like to go scuba diving.

22. A. I would like to meet some persons who are homosexual (men or women).

B. I stay away from anyone I suspect of being "queer."

23. A. I would like to try parachute jumping.

B. I would never want to try jumping out a plane with or without a parachute.

24. A. I prefer friends who are excitingly unpredictable.

B. I prefer friends who are reliable and predictable.

25. A. I am not interested in experience for its own sake.

B. I like to have new and exciting experiences and sensations even if they are a little frightening, unconventional or illegal.

26. A. the essence of good art is in its clarity, symmetry of form and harmony of colors.

B. I often find beauty in the "clashing" colors and irregular forms of modern painting.

27. A. I enjoy spending time in the familiar surroundings of home.

B. I get very restless if I have to stay around home for any length of time.

28. A. I like to dive off the high board.

B. I don't like the feeling I get standing on the high board (or I don't go near it at all).

29. A. I like to date members of the opposite sex who are physically exciting.

B. I like to date members of the opposite sex who share my values.

30. A. Heavy drinking usually ruins a party because some people get loud and boisterous.

B. Keeping the drinks full is the key to a good party.

31. A. The worst social sin is to be rude.

B. The worst social sin is to be a bore.

32. A. A person should have considerable sexual experience before mge.

B. It's better if two married persons begin their sexual experience with each other.

33. A. Even if I had the money I would not care to associate with flight persons like those in the "jet set."

B. I could conceive of myself seeking pleasure around the world with the "jet set."

34. A. I like people who are sharp and witty even if they do sometimes insult others.

B. I dislike people who have their fun at the expense of hurting the feelings of others.

35. A. There is all together too much portrayal of sex in movies.

B. I enjoy watching many of the "sexy' scenes in movies. 


\section{Appendix A Continued}

36. A. I feel best after taking a couple of drinks.

B. Something is wrong with people who need liquor to feel good.

37. A. People should dress according to some standards of taste, neatness, and style.

B. People should dress in individual ways even if the effects are sometime strange.

38. A. Sailing long distances in small sailing crafts is foolhardy.

B. I would like to sail a long distance in a small but seaworthy sailing craft.

39. A. I have no patience with dull or boring persons.

B. I find something interesting in almost every person I talk to.

40. A. Skiing fast down a high mountain slope is a good way to end up on crutches.

B. I think I would enjoy the sensations of skiing very fast down a high mountain slope.

Scoring Key for SSS - Form V

No.

\begin{tabular}{lccrrrrrrrrr}
\multicolumn{10}{c}{ Items } & \multicolumn{10}{c}{ Keyed Items } \\
\hline TAS & 10 & $3 \mathrm{~A}$ & $11 \mathrm{~B}$ & $16 \mathrm{~A}$ & $17 \mathrm{~A}$ & $20 \mathrm{~B}$ & $21 \mathrm{~B}$ & $23 \mathrm{~A}$ & $28 \mathrm{~A}$ & $38 \mathrm{~B}$ & $40 \mathrm{~B}$ \\
ES & 10 & 4B & $6 \mathrm{~A}$ & $9 \mathrm{~A}$ & $10 \mathrm{~B}$ & $14 \mathrm{~A}$ & $18 \mathrm{~A}$ & $19 \mathrm{~B}$ & $22 \mathrm{~A}$ & $26 \mathrm{~B}$ & $37 \mathrm{~B}$ \\
Dis & 10 & $1 \mathrm{~A}$ & $12 \mathrm{~B}$ & $13 \mathrm{~B}$ & $25 \mathrm{~B}$ & $29 \mathrm{~A}$ & $30 \mathrm{~B}$ & $32 \mathrm{~A}$ & $33 \mathrm{~B}$ & $35 \mathrm{~B}$ & $36 \mathrm{~A}$ \\
BS & 10 & $2 \mathrm{~B}$ & $5 \mathrm{~A}$ & $7 \mathrm{~B}$ & $8 \mathrm{~A}$ & $15 \mathrm{~B}$ & $24 \mathrm{~A}$ & $27 \mathrm{~B}$ & $31 \mathrm{~B}$ & $34 \mathrm{~A}$ & $39 \mathrm{~A}$ \\
Total* & 40 & $1 \mathrm{~A}$ & $2 \mathrm{~B}$ & $3 \mathrm{~A}$ & $4 \mathrm{~B}$ & $5 \mathrm{~A}$ & $6 \mathrm{~A}$ & $7 \mathrm{~B}$ & $8 \mathrm{~A}$ & $9 \mathrm{~A}$ & $10 \mathrm{~B}$ \\
& & $11 \mathrm{~B}$ & $12 \mathrm{~B}$ & $13 \mathrm{~B}$ & $14 \mathrm{~A}$ & $15 \mathrm{~B}$ & $16 \mathrm{~A}$ & $17 \mathrm{~A}$ & $18 \mathrm{~A}$ & $19 \mathrm{~B}$ & $20 \mathrm{~B}$ \\
& & $21 \mathrm{~B}$ & $22 \mathrm{~A}$ & $23 \mathrm{~A}$ & $24 \mathrm{~A}$ & $25 \mathrm{~B}$ & $26 \mathrm{~B}$ & $27 \mathrm{~B}$ & $28 \mathrm{~A}$ & $29 \mathrm{~A}$ & $30 \mathrm{~B}$ \\
& & $31 \mathrm{~B}$ & $32 \mathrm{~A}$ & $33 \mathrm{~B}$ & $34 \mathrm{~A}$ & $35 \mathrm{~B}$ & $36 \mathrm{~A}$ & $37 \mathrm{~B}$ & $38 \mathrm{~B}$ & $39 \mathrm{~A}$ & $40 \mathrm{~B}$
\end{tabular}

* The Total score may also be obtained by summing the four subscale scores, but it may be desirable to also score the 40 items and check with the sum of the subscales. 
Appendix B

\section{Brief Sensations Seeking Scale}

1. I would like to explore strange places.

2. I get restless when spending too much time at home.

3. I like to do frightening things.

4. I like wild parties.

5. I would like to take off on a trip with no pre-planned routes or timetables.

6. I prefer friends who are excitingly unpredictable.

7. I would like to try bungee jumping.

8. I would love to have new and exciting experiences, even if they are illegal.

* BSSS from Hoyle, Stephenson, Palmgreen, Lorch, \& Donohew, 2002 p. 405

\section{Brief Sensation Seeking Scale-4}

1. I would like to explore strange places.

2. I like to do frightening things.

3. I like new and exciting experiences, even if I have to break the rules.

4. I prefer friends who are exciting and unpredictable.

* BSSS-4 from Stephenson, Hoyle, Palmgreen, \& Slater, 2003 p. 282 
Appendix C

Caffeine content reported by Erowid (2007) and The Center For Science In The Public

Interest (2007)

Caffeine Content of Bottled Beverages (mg / 12 oz)

\section{ENERGY DRINKS \&}

SYRUPS

Powershot (100 mg per $1 \mathrm{oz})$

Sky Rocket Syrup (100 mg

per $1 \mathrm{oz}$ )

Upshot (200 mg per $2.5 \mathrm{oz})$

Kore Energy Shot (100 mg

per $1.8 \mathrm{oz})$

Spike Shooter (300 mg per 8

$\mathrm{oz})$

Cocaine Energy Drink (280

mg per $8.4 \mathrm{oz}$ ) (now called

Censured Energy Drink)

Redline RTD (250 mg per 8

oz)

Wired X294 (294 mg per 16

$\mathrm{oz})$

Celsius (200 mg per $12 \mathrm{oz}$ )

NOS (250 mg per $16 \mathrm{oz})$

Boo-Koo Energy (360 mg per

$24 \mathrm{oz}$ )

Rockstar Zero Carb (360 mg

per $24 \mathrm{oz}$ )

Spark (120 mg per 8 oz)

Vamp (240 mg per $16 \mathrm{oz}$ )

Rip It Energy Fuel (100 mg per $8 \mathrm{oz}$ )

Crunk (100 mg per 8.3 oz)

Red Bull (80 mg per 8.3 oz)
Red Flash

Aqua Java (50-

$60 \mathrm{mg}$ per 16.9

1200 oz)

Ruby Red

1200 Squirt

Ruby Red

960 Squirt, Diet NSDA 39

666.7 Pepsi

Pepsi, Wild

428.6 Cherry

NSDA $\quad 38.4$

NSDA 38

400

375 Inka Kola

Ale-8-One

ABA $\quad 37$

ABA 37

220.6 Inka Kola, Diet

200 Pepsi, Diet

Pepsi, Wild

187.6 Cherry Diet

NSDA 36

180

Aspen

Nestea Honey

180 Lemon Green

NSDA 36

180 RC Cola, Diet

180

Diet Rite

Coca-Cola,

150 Classic *

CC 34

144.6 Coca-Cola, C2 ABA 34

CC $\quad 34$ 
Coca-Cola,

Cherry *

Sobe Adrenaline Rush (79 mg / $8.3 \mathrm{oz}$ )

AMP Energy Drink

KMX, Orange (75 mg / 8.4

oz)

Full Throttle (72 mg / 8 oz)

Full Throttle, Sugar Free (72 mg / 8 oz)

Bawls Guarana (67 mg per 10 $\mathrm{oz})$

Jolt

Krank 20 (100 mg per 16.9

$\mathrm{oz})$

RC Edge

Vault

XTC Power Drink

Sun Drop, Diet

Aqua Blast (90 mg per 16.9

$\mathrm{oz})$

Sun Drop, Cherry

Sun Drop

Sugar-Free Mr. Pibb

Josta

Kick

Pepsi One
Coca-Cola, Diet

114.2 Cherry ABA 34

Coca-Cola, Diet

ABA 112.5 w/ Splenda $\quad$ ABA 34

Coca-Cola,

ABA 107.1 Vanilla $\quad$ ABA 34

Coca-Cola,

$\begin{array}{llll}\text { ABA } & 100 & \text { Zero } & \text { ABA }\end{array}$

ABA $\quad 100 \quad$ Snapple Peach NSDA 31.5

Nestea Sweet

$\begin{array}{llll}\text { BAW } & 80 & \text { Iced Tea } & \text { NSDA }\end{array}$

Nestea

Unsweetened

$\begin{array}{llll}\text { JC } & 72 & \text { Iced Tea } & \text { ABA }\end{array}$

Snapple Green

CSPI 71 Tea w/Lemon NSDA 24

IBC Cherry

$\begin{array}{llll}\text { NSDA } & 70.2 & \text { Cola } & \text { NSDA }\end{array}$

$\begin{array}{lllll}\text { ABA } & 70 & \text { Barq's } & \text { CC } & 22.5\end{array}$

A \& W Diet

$\begin{array}{llll}\text { DP } & 70 & \text { Creme Soda } & \text { NSDA }\end{array}$

Mistic Lemon

$\begin{array}{llll}\text { NSDA } & 69 & \text { Tea } & \text { NSDA }\end{array}$

Mistic Peach

$\begin{array}{lllll}\text { CSPI } & 63.9 & \text { Tea } & \text { NSDA } & 18\end{array}$

$\begin{array}{lllll}\text { NSDA } & 64 & \text { Cool (Nestea) } & \text { NSDA } & 16.5\end{array}$

Nestea Lemon,

$\begin{array}{llll}\text { ABA } & 63 & \text { Sweet } & \text { ABA }\end{array}$

Nestea Lemon,

$\begin{array}{llll}\text { NSDA } & 58.8 \text { Diet } & \text { ABA } & 16\end{array}$

Nestea

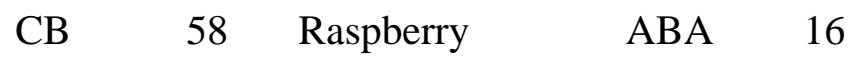

Snapple Sweet

$\begin{array}{llll}\text { NSDA } & 57.6 & \text { Tea } & \text { NSDA }\end{array}$

NSDA 55 Diet Cool (Nestea) NSDA 10.5 
Appendix C continued

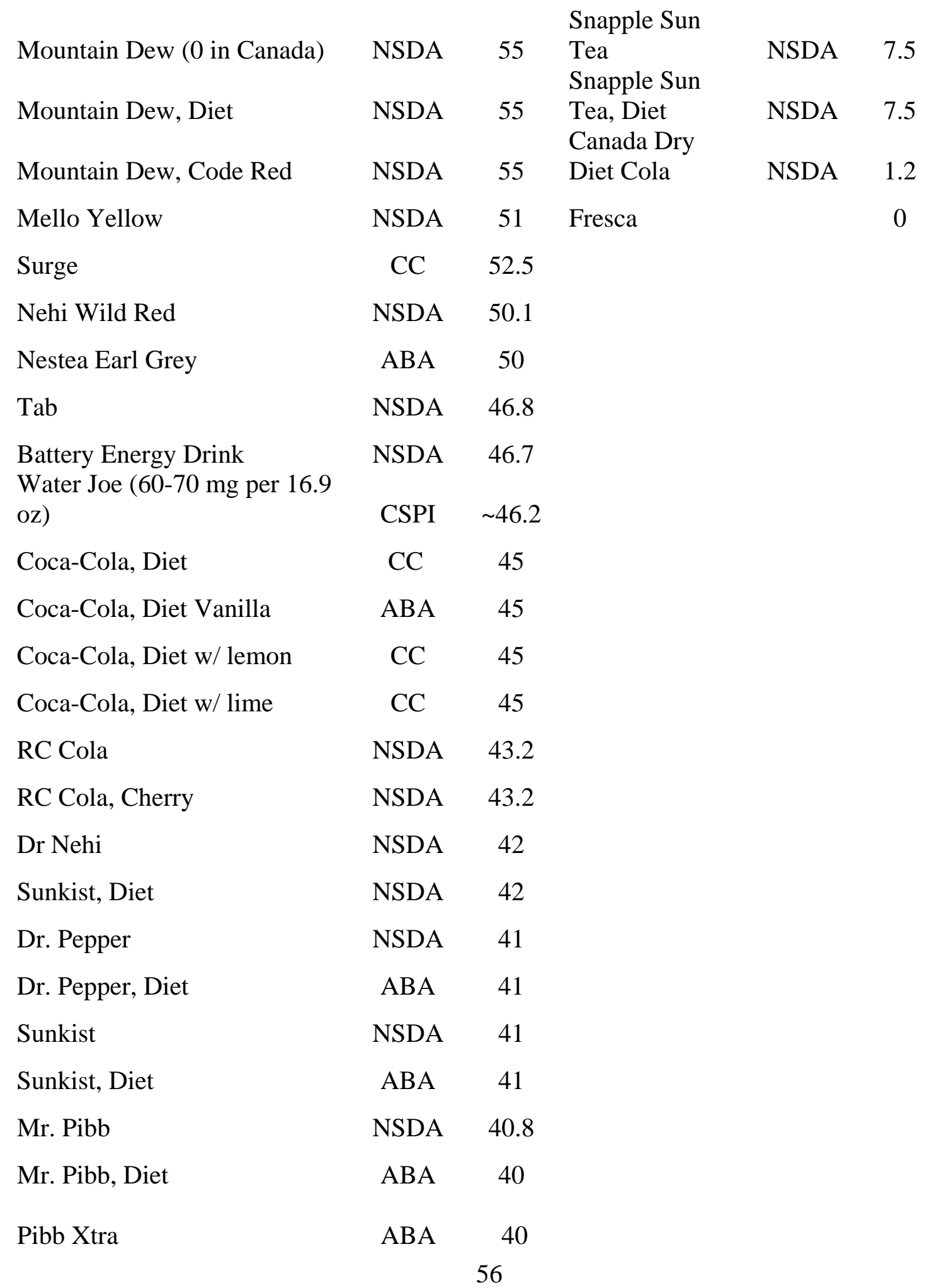


Appendix C continued

Pibb Zero

Mr. Pibb, Diet
ABA $\quad 40$

CC $\quad 40.5$

Caffeine Content of Coffee \& Teas

\begin{tabular}{|c|c|c|c|c|c|}
\hline \multirow{3}{*}{ Percolated (7 oz) } & & & tea iced (12 & & \\
\hline & $\mathrm{CB}$ & 140 & OZS.) & B\&M & 70 \\
\hline & & $115-$ & tea, black ( 6 & & \\
\hline \multirow{2}{*}{ Drip (7 oz) } & $\mathrm{B} \& \mathrm{M}$ & 175 & $\mathrm{oz})$ & CB & 70 \\
\hline & & & tea, green (6 & & \\
\hline \multirow{2}{*}{ Espresso (1.5-2 oz) } & $\mathrm{B} \& \mathrm{M}$ & 100 & $\mathrm{oz})$ & CB & 35 \\
\hline & & & tea, instant (7 & & \\
\hline Brewed (7 oz) & B\&M & 80-135 & $\mathrm{oz})$ & $\mathrm{B} \& \mathrm{M}$ & 30 \\
\hline \multirow[t]{2}{*}{ Instant (7 oz) } & $\mathrm{B} \& \mathrm{M}$ & $65-100$ & $\begin{array}{l}\text { yerba maté, (3 } \\
\text { g teabag) }\end{array}$ & ERO & 24-Oct \\
\hline & \multicolumn{5}{|c|}{ Caffeine Content of Caffeine Pills (mg per tablet) } \\
\hline Vivarin & TCP & 200 & $\begin{array}{l}\text { Vroom Foods } \\
\text { Foosh Mints } \\
\text { Vroom Foods }\end{array}$ & SPFL & 102 \\
\hline No-Doz, Maximum & & & Buzz Bite & & \\
\hline Strength & CSPI & 200 & Chews & SPFL & 102 \\
\hline Dexatrim & TCP & 200 & No-Doz & TCP & 100 \\
\hline $\begin{array}{l}\text { Caffedrine } \\
\text { Awake, Maximum }\end{array}$ & CMF & 200 & Awake & $\mathrm{CMF}$ & 100 \\
\hline Strength & $\mathrm{CMF}$ & 200 & Aqua-Ban & $\mathrm{CMF}$ & 100 \\
\hline Stay Awake & $\mathrm{CMF}$ & 200 & Wake-Ups & TCP & 100 \\
\hline Ultra Pep-Back & CMF & 200 & Aqua-Ban & $\mathrm{CMF}$ & 175 \\
\hline Quick Pep & CMF & 150 & Fat Burner & $\mathrm{CMF}$ & $\sim 55$ \\
\hline
\end{tabular}

ABA

B\&M

BAW

CB
American Beverage Association

Bunker and McWilliams in J Am Diet 74:28-32, 1979

Bawls.com FAQ

Caffeine Blues, by Stephen Cherniske, M.S. 
Appendix C continued

$\begin{array}{ll}\text { CC } & \begin{array}{l}\text { Coca Cola } \\ \text { CMF }\end{array} \\ \text { CSPI } & \text { The Caffeine \& Migraine FAQ } \\ \text { DP } & \text { Center for Science and the Public Interest } \\ \text { ERO } & \text { Eesk Potato Caffeine Guide } \\ \text { IFIC } & \text { International Food Information Council } \\ \text { JC } & \text { Jolt Cola } \\ \text { NSDA } & \text { National Soft Drink Association } \\ \text { SOBE } & \text { Sobe } \\ \text { SPFL } & \text { Sani-Pure Food Labs } \\ \text { TCP } & \text { The Caffeine Page }\end{array}$

Spike Shooter Energy Drink www.spikeshooter.com

Jolt

From product nutritional label
300 mg caffeine retrieved 10-19-2007

220 mg caffeine per 8.4 fl oz per $23.5 \mathrm{oz}$ 


\section{Appendix D}

American Academy of Pediatrics Policy Statement Recommendations

1. Use of performance-enhancing substances for athletic or other purposes should be strongly discouraged.

2. Parents should take a strong stand against the use of performance-enhancing substances and, whenever possible, demand that coaches be educated about the adverse health effects of performance-enhancing substances.

3. Schools and other sports organizations should be proactive in discouraging the use of performance-enhancing substances, incorporating this message into policy and educational materials for coaches, parents, and athletes.

4. Interventions for encouraging substance-free competition should be developed that are more positive than punitive, such as programs that teach sound nutrition and training practices along with skills to resist the social pressures to use performanceenhancing substances.

5. Colleges, schools, and sports clubs should make use of educational interventions that encourage open and frank discussion of issues related to the use of performanceenhancing substances, with the aim of promoting decisions about personal drug use based on principles of fair competition and character rather than on the fear of getting caught.

6. Coaches at all levels, including youth sports, should encourage wholesome and fair competition by emphasizing healthy nutrition and training practices, taking a strong stand against cheating, and avoiding the "win at all costs" philosophy.

7. Inquiries about the use of performance-enhancing substances should be made in a manner similar to inquiries about the use of tobacco, alcohol, or other substances of abuse. Guidelines for patient confidentiality should be followed and explained to the patient.

8. Athletes who admit using performance-enhancing substances should be provided unbiased medical information about benefits, known adverse effects, and other risks. When appropriate, additional testing may be necessary to investigate or rule out adverse medical effects.

9. The pediatric health care professional providing care for an athlete who admits to using a performance-enhancing substance should explore the athlete's motivations for using these substances, evaluate other associated high-risk behaviors, and provide counseling on safer, more appropriate alternatives for meeting fitness or sportsperformance goals.

10. Nonusers of performance-enhancing substances should have their decisions reinforced while establishing an open channel of communication if questions about performance-enhancing substances arise in the future.

11. Pediatric health care professionals should promote safe physical activity and sports participation by providing or making available sound medical information on exercise physiology, conditioning, nutrition, weight management, and injury prevention and by helping to care for sports-related medical conditions and injuries.

* The American Academy of Pediatrics, 2005 p. 1105-1106 
Appendix E

Survey Questionnaire

\section{Caffeine Survey}

1. Sex: (check one) I am a: Male Female

2. I weigh pounds.

3. Ethnic Origin: (check one)

African American Asian Caucasian Hispanic other

4. What is the occupation of your father (male guardian)

What is the occupation of your mother (female guardian)

If you answered retired, deceased, or disabled to any of \#4 then what was his/her occupation prior to that? Father (male guardian)

Mother (female guardian)

5. What is the highest level of education of your father (male guardian) check one

Graduate professional training (e.g. masters, doctorate, MD, chiropractor)

Standard college/university graduation (4 year college degree)

Partial college training (completed at least 1 year of college)

High school graduation (completed high school or trade school)

Partial high school (completed $10^{\text {th }}$ or $11^{\text {th }}$ grades)

Junior high school (completed $7^{\text {th }}$ through $9^{\text {th }}$ grades)

Less than 7 years of school (had not completed $7^{\text {th }}$ grade)

What is the highest level of education for your mother (female guardian) check one

Graduate professional training (e.g. masters, doctorate, MD, chiropractor)

Standard college/university graduation (4 year college degree)

Partial college training (completed at least 1 year of college)

High school graduation (completed high school or trade school)

Partial high school (completed $10^{\text {th }}$ or $11^{\text {th }}$ grades)

Junior high school (completed $7^{\text {th }}$ through $9^{\text {th }}$ grades)

Less than 7 years of school (had not completed $7^{\text {th }}$ grade) 
Appendix E continued

6. Did you participate in high school sponsored activities or other organized activities while in high school? Yes No

If so, which? [Check all that apply.]

$\begin{array}{llcl}\text { basketball } & \text { football } & \text { volleyball } & \text { tennis } \\ \text { wrestling } & \text { softball } & \text { baseball } & \text { soccer } \\ \text { cross country } & \text { track and field } & \text { swimming } & \text { band } \\ \text { rugby } & \text { academic team competition } & \text { choir } \\ \text { journalism } & \text { cheerleading } & \text { gymnastics } & \text { dance } \\ \text { intramural sports } & \text { other } & & \end{array}$

7. Do you participate in college sponsored activities or other organized activities while in college? Yes No

If so, which? [Check all that apply.]

$\begin{array}{llcl}\text { basketball } & \text { football } & \text { volleyball } & \text { tennis } \\ \text { wrestling } & \text { softball } & \text { baseball } & \text { soccer } \\ \text { cross country } & \text { track and field } & \text { swimming } & \text { band } \\ \text { rugby } & \text { academic team competition } & \text { choir } \\ \text { journalism } & \text { cheerleading } & \text { gymnastics } & \text { dance } \\ \text { intramural sports } & \text { other } & & \end{array}$


Appendix E continued

8. Answer the following questions that best describes you. $1=$ strongly agree, $2=$ agree, 3 = neither agree or disagree, 4 = disagree, and 5 = strongly disagree. (circle your response)

\begin{tabular}{|l|c|c|c|c|c|}
\hline & $\begin{array}{l}\text { Strongly } \\
\text { Agree }\end{array}$ & Agree & $\begin{array}{l}\text { Neither } \\
\text { Agree or } \\
\text { Disagree }\end{array}$ & Disagree & $\begin{array}{c}\text { Strongly } \\
\text { Disagree }\end{array}$ \\
\hline I would like to explore strange places & 1 & 2 & 3 & 4 & 5 \\
\hline $\begin{array}{l}\text { I get restless when spending too much } \\
\text { time at home }\end{array}$ & 1 & 2 & 3 & 4 & 5 \\
\hline I like to do frightening things & 1 & 2 & 3 & 4 & 5 \\
\hline I like wild parties & 1 & 2 & 3 & 4 & 5 \\
\hline $\begin{array}{l}\text { I would like to take off on a trip with } \\
\text { no pre-planned routes or timetables }\end{array}$ & 1 & 2 & 3 & 4 & 5 \\
\hline $\begin{array}{l}\text { I prefer friends who are excitingly } \\
\text { unpredictable }\end{array}$ & 1 & 2 & 3 & 4 & 5 \\
\hline I would like to try bungee jumping & 1 & 2 & 3 & 4 & 5 \\
\hline $\begin{array}{l}\text { I would love to have new and exciting } \\
\text { experiences, even if they are illegal }\end{array}$ & 1 & 2 & 3 & 4 & 5 \\
\hline
\end{tabular}

9. I believe that caffeine will help me concentrate when studying. Yes No

10. I believe that caffeine will help keep me awake. Yes No

11. I believe that caffeine will wake me up in the morning. Yes No

12. I believe that caffeine will help me lose weight. Yes No 
Appendix E continued

13. I believe caffeine enhances performance (athletic, academic, artistic, etc). Yes No

14. I believe that caffeine can be harmful to my health and can hurt me. Yes No

15. I believe caffeine is addictive. Yes No

16. I believe that caffeine can disrupt coordination. Yes No

17. I have religious objections to caffeine consumption. Yes No

Have you consumed caffeine in the past year? If no, skip to question 30

If yes, continue with \# 18 below.

18. Have you ever used caffeine to wake up in the morning? Yes No

19. Have you ever used caffeine to stay awake? Yes No

20. Have you ever used caffeine to enhance physical performance? Yes No

21 Have you ever used caffeine to enhance mental performance? Yes No

22. Have you ever used drinks/pills with caffeine to lose weight? Yes No

23. Do you drink beverages with caffeine in them on a daily basis (e.g. coffee, tea, soft drinks, etc)?

Yes No

How many years have you been drinking beverages with caffeine?

Circle one answer:

$\begin{array}{lllllllllll}0 & 1 & 2 & 3 & 4 & 5 & 6 & 7 & 8 & 9 & 10+\end{array}$

24. Have you ever felt/had any of the following reactions after drinking/taking caffeine?

(Check all that apply)

restlessness hot flashes nervousness

can't sleep red faced frequent urination stomach pain

muscle twitching rambling speech can’t concentrate fast heart beat

hives irritated rash panic attack

anxiety obsessive compulsive headache

irregular heart beat hyperactivity

25. Have you felt/had any of the following reactions if you don't get your caffeine?

(Check all that apply)

fatigue (always tired) drowsiness anxiety depressed

sick at stomach vomiting headache cravings for caffeine

irritability 


\section{Appendix E continued}

26. If you drink soft drinks containing caffeine, please answer the questions in the following chart. If you do not, then skip to \# 27.

\section{What is the average number of each drink you have consumed each day over the past} week?

For example: if you drink any Cola's (such as Coke, Pepsi, RC, Dr. Pepper, or Mr. Pibb) how many 8oz drinks, 12 oz drinks, 20 oz drinks, 1 liter bottles, and 2 liter bottles do you consume on average each day?

\begin{tabular}{|c|c|c|c|c|c|c|c|c|c|c|c|c|}
\hline \multirow{6}{*}{$\begin{array}{l}\quad \text { Beverage Type } \\
\text { Colas } \\
\text { (such as Coca-Cola, } \\
\text { Pepsi, RC, Dr. Pepper, } \\
\text { or Mr. Pibb) }\end{array}$} & Size & \multicolumn{11}{|c|}{ Number of Drinks } \\
\hline & 8oz mini drink & 0 & 1 & 2 & 3 & 4 & 5 & 6 & 7 & 8 & 9 & $10+$ \\
\hline & 12oz drink & 0 & 1 & 2 & 3 & 4 & 5 & 6 & 7 & 8 & 9 & $10+$ \\
\hline & 20oz drink & 0 & 1 & 2 & 3 & 4 & 5 & 6 & 7 & 8 & 9 & $10+$ \\
\hline & 1 liter bottle & 0 & 1 & 2 & 3 & 4 & 5 & 6 & 7 & 8 & 9 & $10+$ \\
\hline & 2 liter bottle & 0 & 1 & 2 & 3 & 4 & 5 & 6 & 7 & 8 & 9 & $10+$ \\
\hline \multirow{5}{*}{$\begin{array}{l}\text { Sunkist Orange or } \\
\text { Diet Sunkist Orange }\end{array}$} & 8oz mini drink & 0 & 1 & 2 & 3 & 4 & 5 & 6 & 7 & 8 & 9 & $10+$ \\
\hline & 12oz drink & 0 & 1 & 2 & 3 & 4 & 5 & 6 & 7 & 8 & 9 & $10+$ \\
\hline & 20oz drink & 0 & 1 & 2 & 3 & 4 & 5 & 6 & 7 & 8 & 9 & $10+$ \\
\hline & 1 liter bottle & 0 & 1 & 2 & 3 & 4 & 5 & 6 & 7 & 8 & 9 & $10+$ \\
\hline & 2 liter bottle & 0 & 1 & 2 & 3 & 4 & 5 & 6 & 7 & 8 & 9 & $10+$ \\
\hline \multirow{5}{*}{$\begin{array}{l}\text { Mountain Dew } \\
\quad \text { (any flavor) or } \\
\text { Diet Mountain Dew }\end{array}$} & 8oz mini drink & 0 & 1 & 2 & 3 & 4 & 5 & 6 & 7 & 8 & 9 & $10+$ \\
\hline & 12oz drink & 0 & 1 & 2 & 3 & 4 & 5 & 6 & 7 & 8 & 9 & $10+$ \\
\hline & 20oz drink & 0 & 1 & 2 & 3 & 4 & 5 & 6 & 7 & 8 & 9 & $10+$ \\
\hline & 1 liter bottle & 0 & 1 & 2 & 3 & 4 & 5 & 6 & 7 & 8 & 9 & $10+$ \\
\hline & 2 liter bottle & 0 & 1 & 2 & 3 & 4 & 5 & 6 & 7 & 8 & 9 & $10+$ \\
\hline Mountain Dew MDX & 20 oz drink & 0 & 1 & 2 & 3 & 4 & 5 & 6 & 7 & 8 & 9 & $10+$ \\
\hline Jolt & $23.5 \mathrm{oz}$ can & 0 & 1 & 2 & 3 & 4 & 5 & 6 & 7 & 8 & 9 & $10+$ \\
\hline Vault & 20 oz bottle & 0 & 1 & 2 & 3 & 4 & 5 & 6 & 7 & 8 & 9 & $10+$ \\
\hline \multirow{5}{*}{$\begin{array}{l}\text { Diet Coke (silver can) } \\
\text { or } \\
\text { Diet Pepsi (blue can) }\end{array}$} & 8oz mini drink & 0 & 1 & 2 & 3 & 4 & 5 & 6 & 7 & 8 & 9 & $10+$ \\
\hline & 12oz drink & 0 & 1 & 2 & 3 & 4 & 5 & 6 & 7 & 8 & 9 & $10+$ \\
\hline & 20oz drink & 0 & 1 & 2 & 3 & 4 & 5 & 6 & 7 & 8 & 9 & $10+$ \\
\hline & 1 liter bottle & 0 & 1 & 2 & 3 & 4 & 5 & 6 & 7 & 8 & 9 & $10+$ \\
\hline & 2 liter bottle & 0 & 1 & 2 & 3 & 4 & 5 & 6 & 7 & 8 & 9 & $10+$ \\
\hline $\begin{array}{l}\text { Other Soft Drinks } \\
\text { List }\end{array}$ & List Size & 0 & 1 & 2 & 3 & 4 & 5 & 6 & 7 & 0 & 9 & $10+$ \\
\hline
\end{tabular}


Appendix E continued

27. If you drink energy drinks, please answer the questions in the following chart. If you do not, then skip to \# 28.

\begin{tabular}{|c|c|c|c|c|c|c|c|c|c|c|c|c|}
\hline \multicolumn{13}{|c|}{$\begin{array}{l}\text { What is the average number of each drink you have consumed each day over the past } \\
\text { week? }\end{array}$} \\
\hline \multirow{2}{*}{$\begin{array}{c}\text { Energy Drink Type } \\
\text { Red Bull }\end{array}$} & \multirow{2}{*}{$\frac{\text { Size }}{8.3 \text { oz can }}$} & \multicolumn{11}{|c|}{ Number of Drinks } \\
\hline & & 0 & 1 & 2 & 3 & 4 & 5 & 6 & 7 & 8 & 9 & $10+$ \\
\hline Monster (any flavor) & 16 oz can & 0 & 1 & 2 & 3 & 4 & 5 & 6 & 7 & 8 & 9 & $10+$ \\
\hline Rock Star (any flavor) & 16 oz can & 0 & 1 & 2 & 3 & 4 & 5 & 6 & 7 & 8 & 9 & $10+$ \\
\hline SOBE (any flavor) & 16 oz can & 0 & 1 & 2 & 3 & 4 & 5 & 6 & 7 & 8 & 9 & $10+$ \\
\hline AMP (any flavor) & 16 oz can & 0 & 1 & 2 & 3 & 4 & 5 & 6 & 7 & 8 & 9 & $10+$ \\
\hline Full Throttle (any flavor) & 16 oz can & 0 & 1 & 2 & 3 & 4 & 5 & 6 & 7 & 8 & 9 & $10+$ \\
\hline Shock Wave (any flavor) & 16 oz can & 0 & 1 & 2 & 3 & 4 & 5 & 6 & 7 & 8 & 9 & $10+$ \\
\hline XYIENCE & 16 oz can & 0 & 1 & 2 & 3 & 4 & 5 & 6 & 7 & 8 & 9 & $10+$ \\
\hline Green Tea Energy Drink & 16 oz can & 0 & 1 & 2 & 3 & 4 & 5 & 6 & 7 & 8 & 9 & $10+$ \\
\hline \multirow{2}{*}{ NOS } & 16 oz can & 0 & 1 & 2 & 3 & 4 & 5 & 6 & 7 & 8 & 9 & $10+$ \\
\hline & 11 oz bottle & 0 & 1 & 2 & 3 & 4 & 5 & 6 & 7 & 8 & 9 & $10+$ \\
\hline \multirow{2}{*}{ Bawls Guarana } & 16 oz can & 0 & 1 & 2 & 3 & 4 & 5 & 6 & 7 & 8 & 9 & $10+$ \\
\hline & $10 \mathrm{oz}$ can & 0 & 1 & 2 & 3 & 4 & 5 & 6 & 7 & 8 & 9 & $10+$ \\
\hline 5-hour Energy & 2 oz bottle & 0 & 1 & 2 & 3 & 4 & 5 & 6 & 7 & 8 & 9 & $10+$ \\
\hline $\begin{array}{l}\text { Other Energy Drinks } \\
\text { List }\end{array}$ & $\begin{array}{l}\text { List } \\
\text { Size }\end{array}$ & 0 & 1 & 2 & 3 & 4 & 5 & 6 & 7 & 8 & 9 & $10+$ \\
\hline
\end{tabular}


Appendix E continued

28. If you drink coffee or tea, please answer the questions in the following chart. If you do not, then skip to \# 29.

What is the average number of each drink you have consumed each day over the past week?

\begin{tabular}{|c|c|c|c|c|c|c|c|c|c|c|c|c|}
\hline \multirow{4}{*}{$\begin{array}{c}\text { Type } \\
\text { Brewed Coffee }\end{array}$} & \multirow{2}{*}{$\begin{array}{c}\text { Size } \\
\text { Coffee Cup }\end{array}$} & \multicolumn{11}{|c|}{ Number of Drinks } \\
\hline & & 0 & 1 & 2 & 3 & \multirow{2}{*}{4} & \multirow{2}{*}{$\begin{array}{l}5 \\
5\end{array}$} & \multirow{2}{*}{$\begin{array}{l}6 \\
6 \\
\end{array}$} & \multirow{2}{*}{$\begin{array}{l}7 \\
7 \\
\end{array}$} & \multirow{2}{*}{\multicolumn{2}{|c|}{$\begin{array}{ll}8 & 9 \\
8 & 9 \\
\end{array}$}} & $10+$ \\
\hline & 16 oz cup & 0 & 1 & 2 & 3 & & & & & & & $10+$ \\
\hline & 20 oz cup & 0 & 1 & 2 & 3 & 4 & 5 & 6 & 7 & 8 & 9 & $10+$ \\
\hline Instant Coffee & Coffee Cup & 0 & 1 & 2 & 3 & 4 & 5 & 6 & 7 & 8 & 9 & $10+$ \\
\hline Starbucks Double Shot & $6.5 \mathrm{oz}$ Can & 0 & 1 & 2 & 3 & 4 & 5 & 6 & 7 & 8 & 9 & $10+$ \\
\hline \multirow[t]{4}{*}{ Starbucks Brewed Coffee } & Short & 0 & 1 & 2 & 3 & 4 & 5 & 6 & 7 & 8 & 9 & $10+$ \\
\hline & Tall & 0 & 1 & 2 & 3 & 4 & 5 & 6 & 7 & 8 & 9 & $10+$ \\
\hline & Grande & 0 & 1 & 2 & 3 & 4 & 5 & 6 & 7 & 8 & 9 & $10+$ \\
\hline & Venti & 0 & 1 & 2 & 3 & 4 & 5 & 6 & 7 & 8 & 9 & $10+$ \\
\hline \multirow[t]{4}{*}{ Starbucks Expresso-Hot } & Short & 0 & 1 & 2 & 3 & 4 & 5 & 6 & 7 & 8 & 9 & $10+$ \\
\hline & Tall & 0 & 1 & 2 & 3 & 4 & 5 & 6 & 7 & 8 & 9 & $10+$ \\
\hline & Grande & 0 & 1 & 2 & 3 & 4 & 5 & 6 & 7 & 8 & 9 & $10+$ \\
\hline & Venti & 0 & 1 & 2 & 3 & 4 & 5 & 6 & 7 & 8 & 9 & $10+$ \\
\hline \multirow[t]{4}{*}{ Starbucks Tazo Tea } & Short & 0 & 1 & 2 & 3 & 4 & 5 & 6 & 7 & 8 & 9 & $10+$ \\
\hline & Tall & 0 & 1 & 2 & 3 & 4 & 5 & 6 & 7 & 8 & 9 & $10+$ \\
\hline & Grande & 0 & 1 & 2 & 3 & 4 & 5 & 6 & 7 & 8 & 9 & $10+$ \\
\hline & Venti & 0 & 1 & 2 & 3 & 4 & 5 & 6 & 7 & 8 & 9 & $10+$ \\
\hline Hot Tea & Coffee Cup & 0 & 1 & 2 & 3 & 4 & 5 & 6 & 7 & 8 & 9 & $10+$ \\
\hline Ice Tea & 16 oz bottle & 0 & 1 & 2 & 3 & 4 & 5 & 6 & 7 & 8 & 9 & $10+$ \\
\hline \multirow{3}{*}{$\begin{array}{l}\text { Arizona Ice or Green Tea } \\
\text { (any flavor) }\end{array}$} & 34 oz bottle & 0 & 1 & 2 & 3 & 4 & 5 & 6 & 7 & 8 & 9 & $10+$ \\
\hline & $23.5 \mathrm{oz}$ can & 0 & 1 & 2 & 3 & 4 & 5 & 6 & 7 & 8 & 9 & $10+$ \\
\hline & 16 oz bottle & 0 & 1 & 2 & 3 & 4 & 5 & 6 & 7 & 8 & 9 & $10+$ \\
\hline Diet Lipton Green Tea & 20 oz bottle & 0 & 1 & 2 & 3 & 4 & 5 & 6 & 7 & 8 & 9 & $10+$ \\
\hline Gold Peak Ice Tea & $16.9 \mathrm{oz}$ bottle & 0 & 1 & 2 & 3 & 4 & 5 & 6 & 7 & 8 & 9 & $10+$ \\
\hline $\begin{array}{l}\text { Other Coffee/Tea } \\
\text { List }\end{array}$ & List Size & 0 & 1 & 2 & 3 & 4 & 5 & 6 & 7 & 8 & 9 & $10+$ \\
\hline
\end{tabular}


29. Over the past week, have you consumed caffeine gum, caffeine pills, or caffeine mints? If yes, how many days per week did take them? When you did take them, how many did you take or chew each day?

If you did not use caffeine gum, pills or mints, then skip to \#30.

\begin{tabular}{|c|c|c|c|c|c|c|c|c|c|c|c|c|}
\hline Type & & \multicolumn{11}{|c|}{ Number per day } \\
\hline No Doz & & 0 & 1 & 2 & 3 & 4 & 5 & 6 & 7 & 8 & 9 & $10+$ \\
\hline Ultra Awake & & 0 & 1 & 2 & 3 & 4 & 5 & 6 & 7 & 8 & 9 & $10^{+}$ \\
\hline Hydroxycut & & 0 & 1 & 2 & 3 & 4 & 5 & 6 & 7 & 8 & 9 & $10+$ \\
\hline Caffeine & & 0 & 1 & 2 & 3 & 4 & 5 & 6 & 7 & 8 & 9 & $10^{+}$ \\
\hline Caffeine Alert & & 0 & 1 & 2 & 3 & 4 & 5 & 6 & 7 & 8 & 9 & $10+$ \\
\hline $\begin{array}{l}\text { Yellow Jacket or other } \\
\text { Caffeine Mints }\end{array}$ & & 0 & 1 & 2 & 3 & 4 & 5 & 6 & 7 & 8 & 9 & $10+$ \\
\hline Vivarin & & 0 & 1 & 2 & 3 & 4 & 5 & 6 & 7 & 8 & 9 & $10+$ \\
\hline Warp 9 & & 0 & 1 & 2 & 3 & 4 & 5 & 6 & 7 & 8 & 9 & $10+$ \\
\hline Jolt Caffeine Gum & & 0 & 1 & 2 & 3 & 4 & 5 & 6 & 7 & 8 & 9 & $10+$ \\
\hline $\begin{array}{l}\text { Mini Thin Extreme } \\
\text { Energizer }\end{array}$ & & 0 & 1 & 2 & 3 & 4 & 5 & 6 & 7 & 8 & 9 & $10+$ \\
\hline Pro Plus & & 0 & 1 & 2 & 3 & 4 & 5 & 6 & 7 & 8 & 9 & $10^{+}$ \\
\hline $\begin{array}{l}\text { Other } \\
\text { List }\end{array}$ & & 0 & 1 & 2 & 3 & 4 & 5 & 6 & 7 & 8 & 9 & $10+$ \\
\hline
\end{tabular}

30. Your participation is greatly appreciated. Thank you. 
Appendix F

COVER LETTER

\section{CAFFEINE CONSUMPTION PATTERNS AND BELIEFS OF INCOMING COLLEGE FRESHMEN}

You are being invited to take part in a research study about caffeine consumption patterns and beliefs. You are being invited to take part in this research study because you are a first time college freshmen and have graduated from high school within the past year. If you volunteer to take part in this study, you will be one of about 300 people to do so at the Marshall University. The person in charge of this study is Gary E. McIlvain (PI) of the University of Kentucky. Gary is being guided by Dr. Melody Noland (advisor).

The purpose of this study is to investigate caffeine consumption patterns and beliefs among incoming freshmen. By doing this study, we hope to learn how much caffeine is being consumed, for what purposes, and if there are predictors of caffeine consumption. The research procedures will be conducted at Marshall University in Huntington, WV in UNI 101 (classes for incoming freshmen), and in English 101/102 classes. The total amount of time you will be asked to volunteer for this study is 15 minutes. You, as freshmen at Marshall University, are being asked to complete an anonymous survey that includes questions about caffeine consumption, beliefs toward caffeine, and to complete non-identifying demographic data.

You should NOT participate in this study if you have attended college full time for more than two semesters or have been out of high school for more than one year. You can NOT participate in the study if you are less than 18 years of age.

We cannot and do not guarantee that you will receive any personal benefits from taking part in this study. Your willingness to take part, however, may, in the future, help society as a whole better understand this research topic. If you decide to take part in the study, it should be because you really want to volunteer. You will not lose any benefits or rights you would normally have if you choose not to volunteer. You can stop at any time during the study and still keep the benefits and rights you had before volunteering. Participation or nonparticipation will not affect your grade in this class in any way.

Your information will be combined with information from other people taking part in the study. When we write about the study to share it with other researchers, we will write about the combined information we have gathered. You will not be identified in these written materials. We may publish the results of this study; however, since this is an anonymous survey, your name can not be associated with any data.

This study is anonymous. That means that no one, not even members of the research team, will know that the information you give came from you. If you decide to take part in the study you still have the right to decide at any time that you no longer want to continue. You will not be treated differently if you decide to stop taking part in the study. Before you decide whether to accept this invitation to take part in the study, please ask any questions that might come to mind now. Later, if you have questions, suggestions, concerns, or complaints about the study, you can contact the investigator, Gary E. McIlvain at 304-696-2930 or 606-928-2756 or his advisor, Dr. 


\section{Appendix F continued}

Melody Noland at (859) 257-5827. If you have any questions about your rights as a volunteer in this research, contact the staff in the Office of Research Integrity at the University of Kentucky at 859-257-9428 or toll free at 1-866-400-9428. 
Appendix G

\section{Survey Instruction Script}

You are being asked to participate in research that will help to determine (1) beliefs about caffeine, (2) caffeine consumption patterns, and (3) predictors of caffeine consumption. The research is a self report survey that will take about 10-15 minutes to complete. To participate in this research you must be at east 18 years of age, a freshman at Marshall, and have graduated from high school in the last year. It is very important for you to understand that if you are less than 18 years of age, not a freshman, or did not graduate in the past year, you are not permitted to participate in this research and should not complete the survey. The survey includes questions about demographics, beliefs, and caffeine consumption. If you feel that these types of questions will cause you discomfort you should not participate in the survey. Your participation is completely voluntary and anonymous. Participation will not affect your grade or credit in this course. By completing and returning the survey implies your consent to participate. I will now answer any questions you may have.” 


\section{References}

American Academy of Pediatrics. (2005). Policy Statement: Use of performanceenhancing substances. Pediatrics, 115(4). 1103-1106.

American Psychiatric Association. (1994). Diagnostic and statistical manual of mental disorders ( $4^{\text {th }}$ ed.). Washington, DC: Author. pp. 175-183, 212-215, 439-444, 601-607, 708-709, 833.

Amelia, A. (2006). Remarks on Energy Drinks. Center for Substance Abuse Research. Memorandum of Summary of prepared remarks for FDA public hearings on functional foods.

Adams, T. \& Rini, A. (2007). Predicting 1-year change in body mass index among college students. Journal of American College Health, 55. 361-365.

Bardwell, W., Ziegler, M., Ancoli-Israel, S., Berry, C., Nelesen, R., Druning, A., \& Dimsdale, J. (2000). Does caffeine confound relationships among adreneric tone, blood pressure, and sleep apnea. Journal of Sleep Research,9, 269-272.

Barry, R. J., Johnstone, S. J., Clarke, A. R., Rushby, J.A., Brown, C.R., \& McKenzi, D.N. (2007). Caffeine effects on ERPs and performance in an auditory go/nogo task. Clinical Neurophysiology, 118, 2692-2699.

Bernstein, G.A., Carroll, M.E., thuras, P.D., Cosgrove, K.P., \& roth, M.E. (2002). Caffeine dependence in teenagers. Drug and alcohol Dependance, 66(1), 1-6.

Biggs, S. N., Smith, A., Dorrian, J., Reid, L., Dawson, D., Heuvel, C. VD., \& Baulk, S. (2007). Perception of simulated driving performance after sleep restriction and caffeine. Journal of Psychosomatic Research, 63, 573-577.

Bradley, J. \& Petree, A. (1990). Caffeine consumption, expectancies of caffeineenhanced performance, and Caffeinism symptoms among university students. Journal of Drug Education, 20(4). 319-328.

Brandner, J.M., Behne, M.J., Huesing, B.B., \& Moll, I. (2006). Caffeine improves barrier function of male skin. International Journal of Cosmetic Science, 28, 343-347.

Brice, C. F. and Smith, A. P. (2002). Effects of caffeine on mood and performance: a study of realistic consumption. Psychopharmacology, 164, 188-192. 
Canadian Center for Drug-Free Sport. (1993). National school survey on drugs and sport: Final report. Price-Waterhouse, Gloucester, ON.

Catlin, D. \& Hatton, C. (1991). Use and Abuse of Anabolic and Other Drugs for Athletic Enhancement, Advances in Internal Medicine Cumulative Index volumes 32-36. (pp399-424). Chicago, Year Book Medical Publishers.

Cavadini, C, Siega-Riz, A., \& Pipkin, B. (2000). US adolescent food intake trends from 1965 to 1996. Western Journal of Medicine, 173(6). 378-383.

Cottrell, R., Girvan, J., McKenzie, J. (2002). Principles \& foundations of health promotion and education. ( $2^{\text {nd }}$ ed.). San Francisco: Benjamin Cummings.

Croll, J., Neumark-Sztainer, D., \& Story M. (2001). Health eating: What does it mean to adolescents. Journal of Nutrition Education, 33(4), 193-198.

Crouch, B.I., Caravati, E.M., \& Booth, J. (2004). Trends in child and teen nonprescription drug abuse reported to a regional poison control center. American Journal of health-System Pharmacy, 61(12). 1252-1257.

CSPI Center for science in the public interest caffeine content of food and drugs. (n.d.). Retrieved December 14, 2007 from http://www.cspinet.org/new/cafchart.htm.

CSPI Soft drinks undermining American's health: Teens consuming twice as much liquid candy as milk. (1998). Retrieved May 16, 2005 from http://www.cspinet.org/new/soda_10_21_98.htm.

Cullen, K., Ash, D., Warneke, C., \& Moor C. (2002). Intake of soft drinks, fruit flavored beverages, and fruits and vegetables by children in grades 4 through 6 . American Journal of Public Health, 92(9). 1475-1478.

Dews, P. (Ed). (1984). Caffeine perspectives from recent research. New York: SpringerVerlag.

Dwyer, J., Evans, M., Stone, E., Feldman, H., et al. (2001). Adolescents' eating patterns influence their nutrient intakes. Journal of the American Dietetics Association, 101(7), 798-802. 
Egdochuku, E. \& Akerele, J. (2007). Stimulant use as correlate of abusive behavior among Nigerian undergraduates. College Student Journal, 41(1). 50-58. Retrieved September 10, 2007 from http://web.ebscohost.com/ehost/delivery?vid=5\&hid=17\&sid=665e75a0-16814422-8161.

Ellis, R., Lane, W., \& Olesen, V. (1963). The index of class position: An improved intercommunity measure of stratification. American Sociological Review, 28, 271-277.

Energyfiend caffeine content of starbucks drinks. (n.d.). Retrieved December 14, 2007 from http://energyfiend.com/caffeine-content/starbucks.

Erowid. (2005). Caffeine content of beverages, foods, and medications. http://www.erosid.org/chemicals/caffeine/caffeine_info1.shtml. retrieved 3-25-05.

Fried, E. \& Nestle, M. (2002). The growing political movement against soft drinks in schools. JAMA, 288(17), 2181.

Fernandez-Nieto \& Quirce, S. (2002). Uticaria caused by cola drink. Allergy,57, 967.

French, S., Lin, B, \& Guthrie, J. (2003). National trends in soft-drink consumption among children and adolescents age 6 to 17 years: Prevalence, amounts, and sources, 1977/1978 to 1994/1998. Journal of the American Dietetic Association, 103(10). 1326-1331.

French, S., Story, M., Fulkerson, J., \& Gerlach, A. (2003). Food environment in secondary schools: A la arte, vending machines and food policies and practices. American Journal of Public Health, 93(7), 1161.

Garattini, S. (Ed). (1993). Caffeine, coffee, and health. New York: Raven Press.

Gilliland, K. \& Bullock, W. Caffeine: A Potential Drug of Abuse. In Advances in Alcohol and Substance Abuse. (53-73). New York, Haworth Press (1984).

Graham, T. \& Spriet, L. (1991). Performance and metabolic responses to a high caffeine dose during prolonged exercise. Journal of Applied Physiology, 71(6). 2292-2298.

Greer, F., McLean, C., \& Graham, T. (1998). Caffeine, performance, and metabolism during repeated Wingate exercise tests. Journal of Applied Physiology, 85(4). 1502-1508. 
Griffiths, R., Juliano, L., \& chausmer, A. (2003). Caffeine pharmacology and clinical effects. In: Graham A.W., Schultz, T.K., Mayo-Smith, M.F., Ries, R.K., \& Wilford, b.b. (eds.) Principles of Addiction medicine, $\left(3^{\text {rd }}\right)$ pp. 193-224. Chevy Chase, MD: American Society of Addiction Medicine.

Griffiths, R., Juliano, L., \& chausmer, A. (2005). Information about caffeine dependence. http://www.caffeinedependence.org/caffeine_dependence.html. Retrieved March 25, 2005.

Gurpegui, M., Jurado, D., Luna, J., Fernandez-Molina, C., Moreno-Abril, O., \& Galvez, R. (2007). Personality traits associated with caffeine intake and smoking. www.sciencedirect.com retrieved June 3, 2008. 997-1005.

Harnack, L., Stang, J., \& Story, M. (1999). Soft drink consumption among US children and adolescents: Nutritional consequences. Journal of the American Dietetic Association, 99(4). 436-441.

Health Canada (2005). Fact sheet caffeine and your health. http://www.hc-sc.gc.ca/fnan/securit/facts-faits/caffeine_e.html. Retrieved 11-10-2005.

Hering-Hanit, R. \& Gadoth, N. (2003). Caffeine-induced headache in children and adolescents. Cephalagia, 23, 332-335.

Hollingshead, A. (1957) Two factor index of social position. Hollingshead's index of social index. In (1991) Handbook of Research Design and Social Measurement. (5 ${ }^{\text {th }}$ Ed), Handbook of Research Design and Social Measurement (pp. 462-469). London. Sage Publications.

Hoyle, R. H., Stephenson, M. T., Palmgreen, P., Lorch, E. P., \& Donohew, R. L. (2002). Reliability and validity of a brief measure of sensation seeking. Personality and Individual Differences. 32. 401-414.

Hughes, J., Oliveto, A., Liguori, A., carpenter, J. \& Howard, T. (1998). Endorsement of DSM-IV dependence criteria among caffeine users. Drug and Alcohol Dependence, 52(2). 99-107.

Jacobson, M. (1998). Liquid candy. Nutrition Action News Letter. Washington, 25(9). 8. Full document retrieved from http://www.sspinet.org/sodapop/liquid_candy.htm. Retrieved 5-16-2005, 12 pages. 
Johnson-Green, D., Fatis, M., Sonnek, D., \& Shawchuck, C. (1988). A survey of caffeine use and associated side effects in a college population. Journal of Drug Education 18(3). 211-220.

Josephson, G.W. \& Stine, R.J. (1976). Caffeine Intoxication; a case of paroxysmal atrial tachycardia. JACEP, 5(10), 776-778.

Juliano, L. \& Griffiths, R. (2005). Caffeine. In Lowinson, J.H., Ruiz, P., Millman, R.B., \& Langrod, J.G. (Eds.). Substance Abuse: A Comprehensive Textbook, $\left(4^{\text {th }} \mathrm{ed}\right)$. Pp 403-421. Baltimore: Lippincott, Williams, \& Wilkins.

Kassem, N., Lee, J., Modeste, N., \& Johnston, P. (2003). Understanding soft drink consumption among female adolescents using the Theory of Planned Behavior. Health Education Research, 18(3). 278-291.

Katholi, M., Stormer, E., Stericker, P., Rankin, C., Katholi, C., \& Katholi R. (2003). Zero caffeine for kids. Addiction, 98, 533-537.

Kristiansen, M., Levy-Milne, R., Barr, S., \& Flint, A. (2005). Dietary supplement use by varsity athletes at a Canadian university. International Journal of Sport Nutrition and Exercise Metabolism, 15. 195-210.

Koppelstaetter, F., Poeppel, T. D., Siedentopf, C. M., Ischebeck, A., Verius, M., Haala, I., Mottaghy, F. M., Rhomberg, Pl, Golaszewski, S., Gotwald, T., Lorenz, I. H., Kolbitsch, C., Felber, S., \& Krause, B.J. (2007). Does caffeine modulate verbal working memory process? An fMRI study. NeuoImage, 39, 492-499.

Kuchment, A. (2007) Make that a double: Our desire for caffeinated energy products is soaring. http:/www.msnbc.msn.com/id/19875412/site/newsweek/page/0/. Retrieved October 10, 2007.

Lecos, C. (1984). The latest caffeine scorecard. FDA Consumer.

Lecos, C. (1988). Caffeine Jitters: Some safety questions remain. FDA Consumer.

Llorens, N. (1998). Province-Wide study on the use of various doping methods and substances in high-school sports. Drug Awarness Program Royal Canadian Mounted Police, St-Hubert, Quebec.

McManamy, M.C. \& Schube, P.G. (1936). Caffeine intoxication. New England Journal of Medicine, 215, 616-620. 
Maia, L \& de Mendonca, A. (2002). Does caffeine intake protect from Alzheimer's disease? European Journal of Neurology, 9, 377-382.

Mangus, b. \& Trowbridge, C. (2005) Will caffeine work as an ergogenic aid? The latest research. Athletic Therapy Today, 10(3). 57-62.

Mayo Clinic. (2007). Caffeine: how much is too much? http://www.mayoclinic.com/print/caffeine/NU00600/METHOD=print. Retrieved October 19, 2007.

Mieszkowski, K. (2007). Spiked! From energy drinks to sugary coffee concoctions, kids are consuming more caffeine than ever. How dangerous is it? Readers Digest, July 2007. Retrieved October 19, 2007 from http://rd.com/content/printContent..do?contentId=40746.

Miller, D.C. \& Salkind, N.J. (1991). Handbook of research design and social measurement. ( $5^{\text {th }}$ Ed), Handbook of Research Design and Social Measurement (pp. 462-469). London. Sage Publications.

Miller, K.E. (2008). Wired: Energy drinks, jock identity, masculine norms, and risk taking. Journal of American College health 56(5) 481-489.

Molnar, A. (2003). Parents, are you aware of the commercial activity in your school? Our Children: The National PTA Magazine, 21. 9-11.

Molnar, A. (1999). Cashing in on kids: The second annual report on trends in schoolhouse commercialism: Center for the analysis of commercialism in education. Available at http://www.uwm.edu/Dept/CACE.

Oberstar, J.V., Bernstein, G.A., \& Thuras, P.D. (2002). Caffeine use and dependence in adolescents: One-year follow-up. Journal of Child and Adolescent Psychopharmacology, 1292), 127-135.

Pella, O. (1989). Drug use and attitudes among college students in Benin City, Nigeria. Journal of Drug Education 34(3). 5-13.

Pollak, C. \& Bright, D. (2003). Caffeine consumption and weekly sleep patterns in US seventh-, eithth-, and ninth-graders. Pediatrics, 111(1). 42-46. 
Rampersaud, G., Bailey, L., \& Kauwell, G. (2003). National survey beverage consumption data for children and adolescents indicate the need to encourage a shift toward more nutritive beverages. Journal of the American Dietetic Association, 103(1). 97-100.

Schwenk, T. (2000). Alcohol use in adolescents: The scope of the problem and strategies for intervention. The Physician and Sportsmedicine, 28(6), 71.

Shannon, C., Story, M., Fulkerson, J., \& French, S. (2002). Factors in the school cafeteria influencing food choices by high school students. The Journal of School Health, 72(6). 229-334.

Shultze, M., manson, J., Ludwig, D., et al. (2004). Soft drinks, obesity, and risk for development of Type 2 diabetes. Journal of Clinical Outcomes Management, 11(10). 616-617.

Slomczynski, K.M., Miller, J., \& Kohn M.L. (1981). Stratification, work, and values: A Polish-United States comparison. American Sociological Review, 46, 720-744.

SpikeShooter.com (2007). www.spikeshooter.com. Retrieved October 19, 2007.

Spriet, L., MacLean, D., Dyck, D., Hultman, E, Cederblad, G., \& Graham, T. (1992). Caffeine ingestion and muscle metabolism during prolonged exercise in humans. American Journal of Psycology, 262(6). E891-E898.

Spriet, L. (1995). Caffeine and performance. International Journal of Sport Nutrition, 5. S84-S97.

Stebbins, C., Daniels, J., \& Lewis, W. (2001). Effects of caffeine and high ambient temperature on haemodynamic and body temperature responses to dynamic exercises. Clinical Physiology, 21(5), 528-533.

Stephenson, M. T., Hoyle, R. H., Palmgreen, P., \& Slater, M. D. (2003). Brief measures of sensation seeking for screening and large-scale surveys. Drug and Alcohol Dependence. 72. 279-286.

Story, M., Neumark-Sztainer, D., \& French, S. (2002). Individual and environmental influences on adolescent eating behaviors. Journal of the American Dietetic Association, 40-51. 
Strain, E.C. \& Mumford, G.K. (1994). Caffeine dependence syndrome. Journal of the American Medical Association, 272(13). 1043-1048.

Tibbles, K. (Senior Reporter). (2006, October 31). MSNBC [Television Broadcast]. Retrieved 11-20-2006 from http://www.msnbc.msn.com/id/15403552/.

Turner, H. (2003). Athletic training services and student health on campus: Working together. Journal of American College Health, 51(5), 217.

Tymowski, G. \& Somerville, C. (2002). Attitudes and behaviours of New Brunswick students towards the use of performance-enhancing substances in sport. Drug Awareness Service royal Canadian Mounted Police (J Division).

Venti, J. \& Chambliss, C. (2000). Effects of substance use education programs: A cross cultural comparison of student use. Unpublished research, Ursinus College.

Zagnoni, P. \& Albano, C. (2002). Psychostimulants and epilepsy. Epilepsia, 43(2).

Zuckerman, M. (1979). Sensation seeking: Beyond the optimal level of arousal. Lawerence Erlbaum Association, Hillsdale New Jersey. Pp 10-11; 397-401.

Zuckerman, M. (1971). Dimensions of sensation seeking. Journal of Consulting and Clinical Psychology. 36(1). 45-52.

Zuckerman, M. \& Bone, R. N. (1972). Whatis the sensation seeker? Personality trait and experience correlates of the sensation-seeking scales. Journal of Consulting and Clinical Psychology. 39(2). 308-321. 


\section{Curriculum Vita}

\section{Gary E. McIlvain, MS, ATC}

Glendale, WV November 17, 1970
Birthplace \& DOB

\section{Education}

MS

BS

Diploma

Professional Experience

Aug. 1999 - Present

Aug. 1998 - Aug. 1999

Aug. 1996 - May 1998

Aug. 1994 - May 1996
Health - Middle Tennessee State University, Murfreesboro, TN, August 1999.

Exercise Science/Athletic Training - Lipscomb University, Nashville, TN, December 1993.

Magnolia High School, New Martinsville, WV, June, 1989.

Assistant Professor; Clinical Coordinator, Athletic Training Curriculum, Marshall University, Huntington, WV

Graduate Assistant Athletic Trainer, Middle Tennessee State University, Murfreesboro, TN

Head Athletic Trainer, Lipscomb University, Nashville, TN

Assistant Athletic Trainer, Lipscomb University, Nashville, TN

\section{$\underline{\text { Related Work Experience }}$}

Feb. 2006 - Current

July 31-Current

July 31-August 3, 2006

June 1997 - July 1997

Oct. 1996 - May 1997

May 1996 - July 1996
Medical Director (August 2007-Current) \& Head athletic trainer (February 2006-current)

Athletic Training Consultant to Kentucky Christian University.

Head Athletic Trainer for High School Football Camp at Kentucky University, Grayson, KY.

Vanderbilt University Athletics, Basketball camp head athletic trainer.

Contract Athletic Trainer, Baptist Sports Medicine Center, Nashville, TN

YMCA Wellness Trainer, Murfreesboro, TN. 


\section{$\underline{\text { Awards }}$}

2007-2008 Cambridge Who’s Who Among Executives and Professionals in Athletic Training

2006-2007 Marshall University College of Education and Human Services Faculty Award for Excellence in Scholarship

2006-2007 Cambridge Who's Who Among Executives and Professionals 2005-2006 The Chancellor's List 2005-2006 Manchester Who's Who Among Executives and Professionals 2004-2005 The Chancellor's List 2004-2005 Who's Who Among America's Teachers 2003-2004 Who’s Who Among America’s Teachers

\section{Patents Held}

U.S. Patent \# 5,749, 668 Strengthening Device for Lower Leg/Ankle Currently in final development/marketing.

Patent Pending - for remote controlled oxygen tubing collection device

\section{Publications, Presentions, Inservices, Reviewer, Editing}

1. Jones, M., McIlvain, G., Schaeffer, M., Hoxie, S., \& Giangarra, C. (2008) Pancreatic transection - An unusual youth soccer injury. Athletic Therapy Today 13(5), 17-19.

2. Mcllvain, G. \& Giangarra, C. (2008). Median nerve entrapment: Looking beyond carpal tunnel. Athletic Therapy Today 13(3), 3-6.

3. Martin, D. \& McIlvain, G. March 2, 2008. Invited speakers at Southeast Athletic Trainers' Association annual district meeting. Topic: Neurologic Assessment for Athletic Trainers.

4. January 20-21 (2007) Martin, D., Mcllvain, G., and Sturgill, R. Functional Lung and Heart Evaluation. Tennessee Athletic Trainers' Society Annual meeting. Invited speakers.

5. March 25 (2006) McIlvain, G. \& Martin, D. Concussions: What are we saying? What are we doing? Invited poster presentation.

6. Reviewer for The Strength and Conditioning Journal 2001-Present

7. McIlvain, G. May 27, 2007. Inservice at Elite Rehab and Fitness. Inservice title: The Female Knee \& Reducing the risk of ACL injury."

8. McIlvain, G. \& Giangarra, C. MD March 10, 2007. Presentation/Inservice at Boyd County High School titled The female athlete: Her knee and reducing the risk of injury. 
9. McIlvain, G. \& Martin, D. February 23, 2007. West Virginia Athletic Trainers’ Association Annual Meeting. Poster presentation titled "Concussions: What are we saying... What are we doing?"

10. Martin, D., McIlvain, G., Sturgill, R. January 20, 2007. Tennessee Athletic Trainer's Society Annual Meeting and Clinical Symposium. Invited Speaker for Preconference workshop titled Functional Lung and Heart Evaluation.

11. McIlvain, G., Sturgill, R., \& Martin, D. (2006) Being Prepared for a Medical Emergency. Journal of Physical Education and Recreation (Hong Kong) 12(1). 68-62.

12. McIlvain, G., Proposed Text Reviewer (selected chapters) F. A. Davis \& Company. Emergency Care of Sports Injuries._April, 2006.

13. McIlvain, G., Sturgill, R., \& Martin, D. Program Assessment: A Technological Design \& Approach. Marshall University Assessment Day Poster Presentation. April 5, 2006.

14. McIlvain, G., Martin, D., \& Sturgill, R. Use of Otoscope and Ophthalmoscope For the Athletic Trainer._ Workshop/Presentation at the South East Athletic Trainers Association Symposium \& Members Meeting. March 30-April 2, 2006 . Atlanta, Ga.

15. Sturgill, R., Martin, D., McIlvain, G. Heart Assessment for the Athletic Trainer Workshop._South East Athletic Trainers Association Symposium \& Members Meeting. March 30-April 2, 2006. Atlanta, Ga.

16. Martin, D., McIlvain G., Sturgill, R. Pulmonary Assessment For The Athletic Trainer._(Presentation). South East Athletic Trainers Association Symposium \& Members Meeting. March 30-April 2, 2006. Atlanta, Ga.

17. Martin., D., Sturgill, R., McIlvain, G. Cardiac Assessment for the Athletic Trainer._(Presentation). South East Athletic Trainers Association Symposium \& Members Meeting. March 30-April 2, 2006. Atlanta, Ga.

18. Martin, D., McIlvain, G., Sturgill, R., Thoracic Evaluation for the Athletic Trainer. (Presentation) West Virginia Athletic Trainer's Association Annual Meeting \& Symposium. March 25, 2006.

19. Martin, D., McIlvain, G., Sturgill, R. Thoracic Evaluation for the Athletic Trainer._(Workshop) West Virginia Athletic Trainer's Association Annual Meeting \& Symposium. March 25, 2006.

20. McIlvain, G., Martin, D., Sturgill, R. Prevention Programs For the Female Knee: An Evidence Based Approach For the Practitioner. West Virginia Athletic Trainer's Association Annual Meeting \& Symposium. March 25, 2006.

21. Sturgill, R., McIlvain, G., Martin, D. Radiology For The Athletic Trainer. West Virginia Athletic Trainer's Association Annual Meeting \& Symposium. March 25, 2006.

22. Martin, D., McIlvain, G., \& Sturgill, R. Cooperative Electronic Advising, Student Porfolios, \& Program Assessment: A Technological Approach._West Virginia Association of Colleges for Teacher Educaiton Conference. February 23-24, 2006. 
23. Martin, D. \& McIlvain, G. Neurologic Evaluation Skills: A Return to Basics Kentucky Athletic Trainer's Annual Symposium, January 21, 2006.

24. McIlvain, G., Sturgill, R., \& Martin, D. Medical Emergency: What's Your Plan. $4^{\text {th }}$ Hawaii International Conference on Educaiton, January 5, 2006.

25. Sturgill, R., McIlvain, G., \& Martin, D. Cooperative Electronic Advising and Electronic Portfilios. $4^{\text {th }}$ Hawaii International Conference on Educaiton, January 5, 2006.

26. McIlvain, G. November 4, 2005. Invited speaker at the University of Charleston. Topic: ACL Prevention Programs: An Evidence Based Approach."

27. Martin, D., McIlvain, G., \& Sturgill, R., Adolescent Ankle Injuries; When to Refer, WVAHPERD October, 22, 2005

28. McIlvain, G. \& Sturgill, R. Health Care Provider CPR/FBOA Workshop, WVAHPERD October 22, 2005.

29. Sturgill, R., \& McIlvain, G. Review and update on CPR and FBOA; Health Care Provider. WVAHPERD October 21, 2005.

30. Reviewer for Strength and Conditioning Journal 2003-present

31. Mcllvain, G. The Female Knee, Her ACL, \& Evidence Based Programs Shown to Reduce the Risk. Belfonte Hospital, Ashland, KY. August 4, 2005.

32. McIlvain, G. \& Erwin, M. The Female Knee and the ACL Dilemma. Magnolia High School, New Martinsville, WV. July 9, 2005

33. Martin, D., McIlvain, G., \& Sturgill, R. Heart and Lung Assessment for the Athletic Trainer. Kentucky Athletic Trainer's Annual Symposium, Feb. 19, 2005.

34. McIlvain, G \& Martin, D. July 2004. Ouch, That hurts! Common Injuries in adolescents. WVAPHERD Meeting

35. McIlvain, G \& Martin, D. July 2004. He is Paralyzed! What do I do. Backboarding workshop. WVAPHERD Meeting

36. Martin, D., \& McIlvain, G. February 2004. Use of Otoscope \& Ophthalmoscope for athletic trainers. Presentation at Kentucky Athletic Trainers Association Annual Meeting and Symposium.

37. McIlvain, G. October 2003. Their heart stopped, what do I do? Health Care Provider CPR and Airway Obstruction Updates. WVAPHERD Meeting

38. McIlvain, G., Martin, D., July 2002 Workshop in CPR and Airway Obstruction. WVAPHERD Meeting

39. Martin, D \& McIlvain, G. October 2003, Cooperative Electronic Advising. WVAPHERD Higher Education Seminar.

40. McIlvain, G. October 2002, Review for McGraw Hill. Reviewed text titled Essentials of Athletic Training, $5^{\text {th }}$ ed.

41. McIlvain, G., Martin, D., Toney, M. July 2002 CPR and Choking Certification WVAPHERD Meeting

42. McIlvain, G. July 2002. Their not breathing, what do I do? Health Care Provider CPR and Airway Obstruction Updates. WVAPHERD Meeting

43. McIlvain, G. July 2002 Using Technology in HPER and Sciences Classes WVAPHERD Higher Education Seminar 
44. Martin, D., \& McIlvain, G. May 2002. Otoscope/Ophthalmoscope Presentation at Mid-Atlantic Athletic Trainers Association Annual Meeting and Symposium.

45. McIlvain, G. 2002. Technology Workshop; Using Spring Visor (Palm Pilot) for Power Point Presentations, Marshall University

46. McIlvain, G., Martin, R. D., Toney, M. 2000. Health Care Provider CPR instruction for Cable Midland High School Students, Huntington, WV

47. McIlvain, G., Martin, R. D., Toney, M. 2000. Health Care Provider CPR instruction for Recreation Sport Graduate Students, Marshall University

48. McIlvain, G. 2000. Technology Workshop; Using Miniature Laptop and External CD Writers, Marshall University

49. McIlvain, G. 2000. Technology Workshop; Using Digital Cameras for Digital Movies/Pictures and Power Point, Marshall University

50. Elrod, B., MD, Stowers, MD, Snoddy, C, MS, ATC, McIlvain, G, ATC; 1997, Educational Series on ACL injuries in female athletes; Nashville Channel 4 News Cast. Mechanism, Causes, Mental Reactions, Surgery, \& Recovery.

51. McIlvain, G. 1996. How to Choose and Care For Exercising Shoes; Running Shoes, Walking Shoes, and Cross Trainers, TOPS (Take Off Pounds Sensibly, Weight Loss Group)

52. McIlvain, G. 1996. Proprioceptive Neuromuscular Stretching; How and Why, TOPS (Take Off Pounds Sensibly, Weight Loss Group) 